\title{
Development of a spatially explicit, individual- based model of marine fish early life history
}

\author{
S. Hinckley ${ }^{1, *}$, A. J. Hermann ${ }^{2}$, B. A. Megrey ${ }^{1}$ \\ 'NOAA, National Marine Fisheries Service, Alaska Fisheries Science Center, 7600 Sand Point Way, NE Seattle, \\ Washington 98115 , USA \\ ${ }^{2}$ Joint Institute for the Study of the Atmosphere and the Oceans, University of Washington, WB-10, Seattle, \\ Washington 98195 , USA
}

\begin{abstract}
A growing body of evidence suggests that survival of the planktonic early life stages of marine fish varies spatially, often in concordance with mesoscale and larger circulation patterns and with spatıal variation in biotic and abiotic factors. Environmental variation experienced by individuals may contribute to variance within the population. Detailed spatial information about life histories cannot be obtained however, by simply subjecting individuals to identical time series of environmental variates, or adding random noise to the mean values of those variates. In this paper, we present a numerical biophysical model to address this problem. The model combines a 3-dimensional hydrodynamic model with a probabilistic, life-stage model of young fish. The oceanographic model is an eddyresolving, semi-spectral primitive equation model (SPEM) adapted for Shelikof Strait and the western Gulf of Alaska, USA. The biological component is an individual-based model (IBM) which follows each fish through its first 3 mo of life. The 2 models are coupled via a float-tracking algorithm, which advects each fish through the model grid based on the time-varying velocity field derived from the SPEM model, and returns information to the IBM on any physical variables of interest (e.g. temperature and salinity) at the individual's new location. These variables are used to drive biological processes in the JBM. Simulation 1 demonstrates how a probabilistic lBM using Lagrangian temperature information derived from float tracking can yield significantly different biological results than the same model with constant temperature, or a model where all individuals are subjected to identically increasing time series of temperature. In Simulation 2 we compare the float tracks and growth of individuals using a scenario of constant depth for each life stage versus algorithms that include mechanisms producing variable depth. These mechanisms differ for each life stage (e.g. changes in depth due to development of eggs, or diel migration of feeding larvae). This simulation shows that inclusion of specific mechanisms which determine depth of individual eggs or larvae at particular periods of their development are important in determining the direction of horizontal advection, and the history of exposure to environmental variables for each individual. Simulation 3 compares modeled distributions of the early life stages with distributions derived from field surveys.
\end{abstract}

KEY WORDS: Biophysical model - Recruitment Walleye pollock Fisheries oceanography

\section{INTRODUCTION}

Spatial variability in circulation and environmental conditions which causes differential growth and mortality among individuals is thought to be important to overall levels of recruitment. For many marine fish species with planktonic early life stages, mesoscale and larger circulation features appear to influence the suc-

•E-mail:sarahh@afsc.noaa.gov cess of a year class (Incze et al. 1989, Kendall \& Nakatani 1992, Schumacher et al. 1993, Bograd et al. 1994), especially in regions with strong and variable currents. Circulation factors may act directly, through transport of early life stages to appropriate nursery areas, or indirectly, by mediating encounters of young fish with prey and predators. In regions with complex horizontal patterns, the trajectories of individual fish may differ widely, causing individual histories of exposure to environmental variables (such as temperature, salinity, predators and prey) also to differ. This may 
lead to variability in growth or the probability of survival among individuals.

Numerical biophysical modeling can help us to explore these mechanisms and their interactions and may lead us to a better understanding of recruitment. An appropriate model should include spatial factors, such as ocean circulation patterns and distributions of abiotic and biotic factors. In this paper, we present a spatially explicit biophysical model which describes the dynamics of survival and growth of the early life stages of a marine fish species. The biophysical model consists of 2 components: an individual-based biological model (IBM) of the fish's early life stages, and a 3dimensional hydrodynamic model (a semi-spectral primitive equation model (SPEM), Haidvogel et al. 1991)]. The biological IBM models each individual's interactions with the abiotic environment, and preserves the unique trajectory through time and space of each individual, as well as its growth and survival. The hydrodynamic model is capable of reproducing mesoscale and larger circulation features, of advecting individuals through space in a reasonably accurate manner, and of producing spatial distributions of important physical factors such as temperature and salinity.

Ecologists increasingly use models which deal explicitly with individuals in order to generate system dynamics (DeAngelis \& Gross 1992, Judson 1994). This increase has arisen for several reasons. Simple, aggregated models ignore 2 basic aspects of biology: that all individuals are different, and that interactions between individuals take place locally (Huston et al. 1988, DeAngelis \& Gross 1992, Judson 1994). However, analytical approaches to such issues are often intractible. The rise of IBMs has been facilitated by increases in computer power over the past decade, which allows the simultaneous tracking of many individuals and their attributes. This was previously impossible.

IBMs are usually divided into 2 main types: 'i-state distribution' models and 'i-state configuration' models (Metz \& Diekmann 1986, Caswell \& John 1992). The i-state distribution models aggregate individuals into age, size or stage groups, within which all individuals are assumed to be homogenous. The i-state configuration models treat each individual as a unique entity. However, i-state distributions can be derived from istate configuration models by reducing the configuration to a distribution function.

The advantages and disadvangtages of i-state configuration models have been described by DeAngelis \& Rose (1992). They conclude that these models are useful in studying problems where the population size is small and there is high sensitivity to initial conditions, in large or small populations where there is stochasticity in growth and mortality and where fluctua- tions in $\mathrm{i}$-state variables may be amplified in some individuals relative to other individuals, or where all individuals at the same point in state-space are not assumed to encounter the same environment due to incomplete population mixing Under these circumstances, i-state configuration IBMs are able to capture dynamics that are lost when aggregated models are used. Such models enable exploration of processes at higher levels of complexity at different time and space scales and the inclusion of many different $i$-state variables. Recent examples of the IBM approach include DeAngelis et al. (1991), Rice et al. (1993), and Rose \& Cowan (1993).

There are certainly disadvantages and difficulties in the use of the i-state configuration models. The biological data needs increase greatly (although parameters are usually easier to understand), and it is often very difficult to obtain truly individual information. There are few measurements over time on the same individual. There are also practical limits to the attributes that can be measured for each fish (Van Winkle et al. 1993) Selection on and heritability of traits is often not addressed (Chambers 1993). Often modelers are forced to use population-level estimates of parameters, such as means and variances of an attribute, or even simply the mean, due to the lack of truly individual information (Pepin \& Miller 1993). In the case of spatially explicit models, spatially varying estimates of parameters are difficult to obtain. Moreover, these models are less amenable to standard techniques of mathematical analysis than aggregated models. Results can be voluminous and difficult to interpret. The choice of output variables to examine is often not obvious, and interactions among variables can be confusing. The meaning of standard statistical methods used on model output is a largely undeveloped area. Finally, these models can also require massive amounts of computing resources (CPU time, storage and memory).

There is debate about whether i-state configuration models are so specific to a particular system that they preclude generality (Smith 1974, Komnicki 1992), or conversely, whether they can actually unify ecological theory (Huston et al. 1988). In the end, the choice of whether to use i-state configuration, i-state distribution, or simple aggregated population models depends on the specific objectives of the study and the attributes of the system under examination. Here, we choose to use an i-state configuration model.

Historically, ecological models intended to predict mean population properties which vary in space have done so through the use of a spatially fixed (Eulerian) numerical grid. While straightforward stochastic methods may allow for random influences of a fluctuating environment (Nisbet \& Gurney 1982), they cannot eas- 
ily deal with systematic changes in the enviranment which result from an individual's advection or migration into new habitats over the course of its lifetime. Models involving heterogeneous spatial effects are generally analytically intractable, and necessitate the use of numerical simulation (DeAngelis \& Rose 1992). The inclusion of spatial variability in IBMs is relatively recent (Werner et al. 1993, 1995, Tyler \& Rose 1994). Thus far, most IBMs do not include spatial tracking, that is, they include no information about where the individuals exist in their environment as they grow and develop. Those that are spatially explicit have tended to have little biological detail (Neill 1979 , Bartsch et al. 1989, Walters et al. 1992,

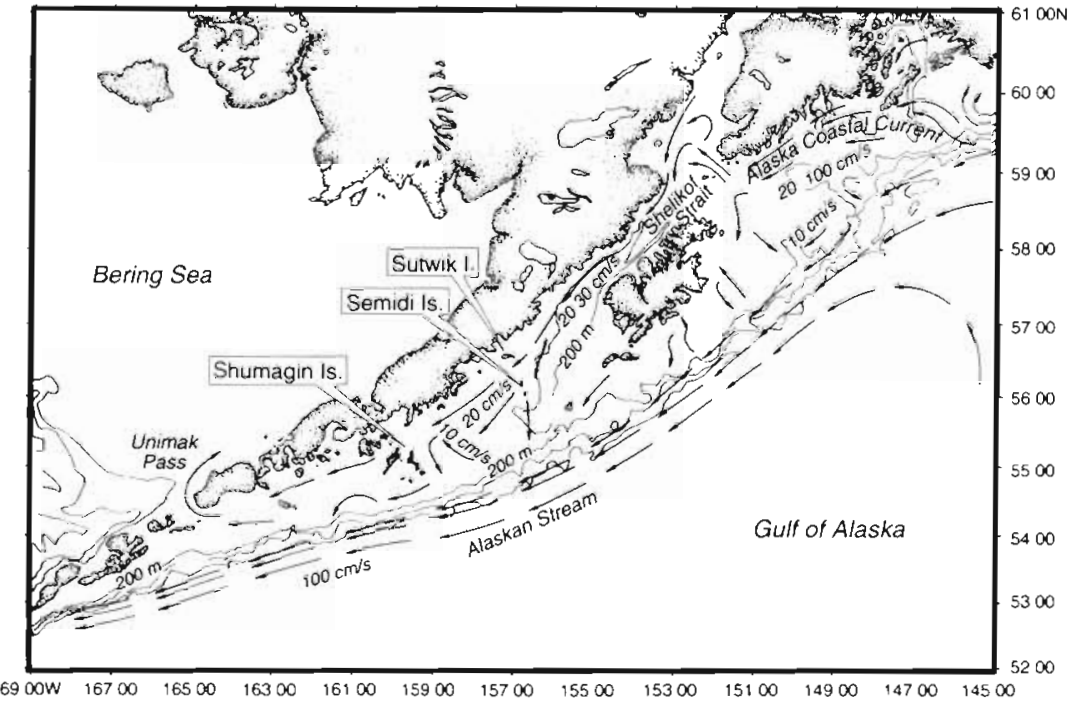

Fig. 1. Gulf of Alaska, USA, and study region
The inclusion of spatial history is crucial for many marine species. Different life stages may occupy substantially different physical environments. For example, eggs may be laid in a near-bottom, near-coastal environment, while larvae develop near the surface in shallow continental shelf waters and juvenile and adult years are spent in the deeper ocean. Even for marine species with no appreciable horizontal transport, systematic vertical migration through light, temperature and prey concentration gradients may play a significant role in determining growth and survival (Sclafani et al. 1993). Movement of individuals may be due purely to physical forcing, for example in the passive early life stages, or to active responses to the biotic or abiotic environment, for example in later life stages, which are capable of controlling their position.

This biophysical modeling effort focuses on walleye pollock Theragra chalcogramma, a commercially important gadoid, in the western Gulf of Alaska Yearclass strength of this species is thought to be set within the first few months of life (Bailey \& Spring 1992). Spawning occurs in Shelikof Strait in April (Fig. 1), and the pelagic eggs and larvae are carried southwest by powerful currents to a juvenile nursery area near the Shumagin Islands. Although the transport of early life stages is dominated by advection, there exists a high degree of horizontal and vertical variability of the currents in time and space, and the occurrence of mesoscale eddies, convergence zones, plumes and a deep counterflow are thought to affect the growth and survival of young pollock. Factors thought to be important to recruitment include the likelihood of advection to the nursery area, retention in mesoscale eddies, storm frequency and intensity during certain life history stages, variation in prey production, overlap with predators and prey and the interactions of these processes.

The physical model will be described briefly as a more complete description exists elsewhere. The preliminary biological model (IBM), as it was used in these simulations, will be described in detail, as will the method of coupling the models. We also describe several model simulations. Simulation 1 uses the uncoupled biological and physical models, with information from the physical model fed into the biological model to assess the impact of Lagrangian time series of temperature. Simulation 2 uses a dynamic coupling of these same 2 models, and assesses the importance of vertical movement of individuals in a manner that differs by life stage. Simulation 3 (using the fully coupled models) was done to assess how well the model predicted the distribution of several life stages for a particular year, and the general pattern of distributions of life stages as determined by survey data.

\section{THE PHYSICAL MODEL}

The hydrodynamic model utilized, described in Hermann \& Stabeno (1996), was a 3-dimensional, prognostic, rigid-lid, eddy-resolving model of velocity and salinity fields in the northern Gulf of Alaska. The model solved the hydrostatic, primitive hydrodynamic equations, with wind forcing distributed over the top $20 \mathrm{~m}$ of the water column, and buoyancy forcing (due to runoff) along the coastline of Alaska. Currents generated by the model have been compared with those measured by moored current meters and satellitetracked drifting buoys (Stabeno \& Hermann 1996). The model reproduces dominant circulation features in- 
cluding the Alaska Coastal Current, with appropriate cross-shelf structure, vertical shear, and mean transport. Floats tracked at $40 \mathrm{~m}$ using filtered model velocity fields compared favorably with observed drifter tracks at that depth (Fig. 11 in Stabeno \& Hermann 1996). Discrepancies between the model and data were generally due to the formation of mesoscale eddies in the model at different times than those observed, although eddy statistics (e.g. rate of eddy formation, location) were similar for both.

\section{THE BIOLOGICAL MODEL}

The biological model is divided into 3 life stages between spawning and metamorphosis to the juvenile stage: the egg stage, the yolk-sac larval stage, and the feeding larval stage. Processes such as mortality and growth for each life stage are described in subsequent sections. These processes and the parameters associated with them are based, for the most part, on a wide variety of field and laboratory observations on this population. Based on these processes, population size, length and weight are updated once per day $\left(\Delta t_{\mathrm{lBM}}=24 \mathrm{~h}\right)$. Positions of individuals are updated more frequently, as described in the section on 'Biophysical coupling,' see below. A summary of parameter values is presented in Table 1.

\section{Egg stage}

Eggs are released in the model on day of year (DOY) 90 or 92 . Eggs are randomly assigned an egg diameter (from a normal distribution with a mean of es =

Table 1. Parameters for individual-based biological model (IBM)

\begin{tabular}{|c|c|c|}
\hline & Parameter & Value \\
\hline es & Mean egg diameter at start of simulation ( $\mathrm{mm}$ ) & 1.314 \\
\hline$e s^{2}$ & Variance of initial egg diameter (mm) & 0.0002 \\
\hline$z_{\mathrm{e}}$ & Instantaneous daily mortality of eggs $\left(\mathrm{d}^{-1}\right)$ & $0.25^{\mathrm{a}}$ \\
\hline$z_{y}$ & Instantaneous daily mortality of yolk-sac larvae $\left(\mathrm{d}^{-1}\right)$ & $0.15^{\circ}$ \\
\hline$\delta_{\mathrm{FFR}}$ & Degree days to first-feeding readiness & 18.0 \\
\hline$\delta_{\mathrm{PNR}}$ & Degree days to point of no return & 67.5 \\
\hline$z_{1}$ & Instantaneous daily mortality of feeding larvae $\left(\mathrm{d}^{-1}\right)$ & $0.05^{\mathrm{a}}$ \\
\hline$Q_{10}$ & $Q_{10}$ for consumption, teedıng metabolism and routine metabolism & 2.0 \\
\hline$T_{\text {inat }}$ & Initial temperature for temperature effect on consumption, feeding metabolism and routine metabolism $\left({ }^{\circ} \mathrm{C}\right)$ & 4.5 \\
\hline$s^{2} c$ & Variance of consumption ( $\mu \mathrm{g}$ dry wt $\mathrm{d}^{-1}$ ) & 25.0 \\
\hline$\gamma$ & Oxycaloric equivalent $\left(\mathrm{cal} \mu \mathrm{l} \mathrm{O}^{2}\right.$ ) & 0.00463 \\
\hline$\beta$ & Calorie to microgram conversion ( $\mathrm{mg} \mathrm{cal}^{-1}$ ) & 227.0 \\
\hline$\alpha$ & Assimilation efficiency & 0.8 \\
\hline$S_{M}$ & Size at metamorphosis from larva to juvenile ( $\mathrm{mm}$ ) & 22.0 \\
\hline$v$ & Molecular viscosity of seawater $\left(\mathrm{g} \mathrm{cm}^{-1} \mathrm{~s}^{-1}\right)$ & 0.161 \\
\hline$\Delta t_{\mathrm{c}}$ & Time step for depth algorithm in biophysical coupling (h) & 1.0 \\
\hline$\Delta t_{\text {ita }}$ & Time step for float tracking algorithm (h) & 0.2 \\
\hline$\Delta t_{\mathrm{IBM}}$ & Time step for individual-based model (h) & 24.0 \\
\hline$s S_{y s i}$ & Swimming speed of yolk-sac larvae (body lengths $\mathrm{s}^{-1}$ ) & 0.3 \\
\hline$s s 1_{\mathrm{fd} l}$ & Mean swimming speed of feeding larvae less than $6 \mathrm{~mm}$ SL (body lengths $\mathrm{s}^{-1}$ ) & 0.1 \\
\hline$s s 2_{\mathrm{fdl}}$ & Mean swimming speed of feeding larvae larger than $6 \mathrm{~mm}$ (body lengths $\mathrm{s}^{-1}$ ) SL & 0.08 \\
\hline$S_{\text {ssidl }}^{2}$ & Variance of swimming speed of feeding larvae greater than $6 \mathrm{~mm} \mathrm{SL}$ (body lengths $\mathrm{s}^{-1}$ ) & 0.28 \\
\hline$S_{\mathrm{dm}}$ & Size at which feeding larvae begin diel migration $(\mathrm{mm})$ & 6.0 \\
\hline$L_{\min }$ & Minimum preferred light level (mmol $\mathrm{m}^{-2} \mathrm{~s}^{-1}$ ) & 6.0 \\
\hline$L_{\max }$ & Minimum preferred light level $\left(\mathrm{mmol} \mathrm{m}^{-2} \mathrm{~s}^{-1}\right)$ & 13.0 \\
\hline$k$ & Extinction coefficient & 0.16 \\
\hline mld & Mixed layer depth & 20 \\
\hline sd & Standard deviation of nighttime feeding larval depth distribution (m) & 3.65 \\
\hline dur $_{1}$ & Duration of Simulation $1(\mathrm{~d})$ & 45 \\
\hline dur $_{2}$ & Duration of Simulation 2 (d) & 140 \\
\hline dur $_{3}$ & Duration of Simulation 3 (d) & 70 \\
\hline $\mathrm{n}_{1}$ & Number of individuals in Simulation 1 & 80000 \\
\hline $\mathrm{n}_{2}$ & Number of individuals in each run of Simulation 2 & 3000 \\
\hline $\mathrm{n}_{3}$ & Number of individuals in Simulation 3 & 1600 \\
\hline $\operatorname{dep}_{e}$ & Depth of eggs used in the null model, Simulation $1(\mathrm{~m})$ & 200 \\
\hline $\operatorname{dep}_{\mathrm{ys}}$ & Depth of yolk-sac larvae used in the null model, Simulation $1(\mathrm{~m})$ & 100 \\
\hline $\operatorname{dep}_{\{\mathrm{dl}}$ & Depth of feeding larvae used in the null model, Simulation 1 (m) & 40 \\
\hline
\end{tabular}


$1.314 \mathrm{~mm}$ and a variance, $e s^{2}=0.0002$; Hinckley 1990). Eggs are assigned an initial spawning depth of $200 \mathrm{~m}$. Actual spawning depth and time varies; here, we use an average for the purpose of simplification. Changes in egg depth due to changes in density with development will be discussed in the section on 'Biophysical coupling.' Initial egg density is set equal to the water density at the depth of spawning (which is a function of salinity; see Eq. 15). The egg stage lasts about 2 wk at $5^{\circ} \mathrm{C}$ (Haynes \& Ignell 1983).

The daily probability of survival for an egg is

$$
s_{e j}=e^{-z}
$$

where $s_{\mathrm{e}}$ is the probability of survival of the egg on day $j_{\text {; }}$ and $z_{\mathrm{e}}$ is the instantaneous daily mortality rate of eggs (a constant).

A random number (from a uniform distribution) between 0 and 1 is generated, and if this number is larger than the probability of survival on day $j$, the egg dies. If the random number is smaller or equal, the egg survives. Once an egg or larva dies, it is dropped from the simulation.

The egg development process is divided into 21 stages (Blood et al. 1994) in order to compute the development rate (from age and temperature) and the egg density from available data. The egg stage is a function of age and temperature:

(if egg age is less than $20 \mathrm{~h}$ )

$$
e=-2.9935+3.0438 \cdot \sqrt[3]{a}+0.0172 \cdot a T
$$

(if egg age is greater than or equal to $20 \mathrm{~h}$ )

$$
\begin{gathered}
e=-4.8019+1.0851 \sqrt{ } a+0.0051 \text { a } T+ \\
0.1595 T \sqrt{ } a
\end{gathered}
$$

where $e$ is egg stage; $a$ is egg age $(\mathrm{h})$; and $T$ is temperature $\left({ }^{\circ} \mathrm{C}\right)$.

In order to calculate density, eggs are separated into 7 groups based on their stage of development (Kendall \& Kim 1989), as follows:

$$
\begin{aligned}
& \text { Group } 1=\text { Stages } 1-6 \text { (cell stages) } \\
& \text { Group } 2=\text { Stages } 7-8 \text { (early germ ring stages) } \\
& \text { Group } 3=\text { Stages } 9-12 \text { (germ ring stages) } \\
& \text { Group } 4=\text { Stages } 13-15 \text { (middle stages) } \\
& \text { Group } 5=\text { Stages } 16-18 \text { (early late stages) } \\
& \text { Group } 6=\text { Stages } 19-21 \text { (late stages) } \\
& \text { Group } 7=\text { Hatching. }
\end{aligned}
$$

Absolute changes in density of eggs with development, corrected for the depth of spawning, are calculated from laboratory studies reported in Kendall \& Kim (1989) for Type II eggs. (Type II eggs are the most common class of pollock eggs and are heavier in the early developmental stages than are Type I eggs.) Egg density increases with developmental stage until just before hatching, when density drops. When the egg reaches Stage 21 (Group 7), it hatches, and the individual passes into the yolk-sac larval stage. Egg specific gravities are used to calculate the depth of each individual egg at each time step, as discussed in the section 'Biophysical coupling.'

\section{Yolk-sac larval stage}

The size at hatch of an individual is determined by the egg size (Hinckley 1990):

$$
l=0.483+2.613 \cdot d
$$

where $l$ is larval standard length (SL) (mm), and $d$ is egg diameter ( $\mathrm{mm}$ ).

Larval dry weight at hatch is a function of standard length (Yamashita \& Bailey 1989):

$$
W=0.1754 \cdot 1^{3.615}
$$

where $W$ is larval dry weight $(\mu \mathrm{g})$.

The daily probability of survival of yolk-sac larvae is determined in the same way as described in 'Egg stage,' using Eq. (1), with $z_{y}$ the instantaneous daily mortality rate for yolk-sac larvae.

Degree days are used to determine when the yolksac larva reaches first-feeding readiness and the point of no return (the time at which starvation is irreversible, i.e. death from starvation is inevitable). Degree days are accumulated for every day after hatch using temperature information from the physical model for each location and time step. If degree days are less than the number of degree days to firstfeeding readiness $\left(\delta_{\mathrm{FFR}}=18.0\right)$, larval age is incremented $1 \mathrm{~d}$. The parameter, $\delta_{\Gamma \mathrm{F},}$, was adjusted to produce an age at first-feeding readiness comparable to laboratory studies $1 G$. Theilacker, Alaska Fisheries Science Center, 7600 Sand Point Way NE, Seattle, WA 98115, USA, pers. comm.). The parameter value used was less than what would be indicated by the laboratory studies for degree days, indicating a possibly nonlinear relationship between degree days and yolksac larval development times. Future versions of the yolk-sac larval section of the model will be bioenergetically based.

Once the larva is ready to feed, the probability of feeding on each day, a linearly increasing function of age, is compared with a random number (from a uniform distribution) between 0 and 1 . If the random number is greater than the probability of feeding, the larva does not feed. In this case, a new length is calculated which reflects a percent decline in size each day (Bailey \& Stehr 1986):

$$
l_{j+1}=l_{j}-\left(0.015 \cdot l_{j}\right)
$$


where $l_{j+1}$ is larval standard length on day $j+1(\mathrm{~mm})$; and 1 , is larval standard length on day $j(\mathrm{~mm})$.

Shrinkage in length of yolk-sac larvae is possible because the notochord, being cartilaginous, is somewhat flexible. Larval dry weight is calculated based on length as in Eq. (5), above.

If the random number is less than or equal to the probability of feeding, the larvae feeds and makes the transition to the feeding larval stage. length and weight changes are then calculated based on the procedures discussed below ('Feeding larval stage') for the day of transition. If the larva passes the point of no return $\left(\delta_{P_{N R}}=67.5\right.$ degree days; Bailey \& Stehr 1986) without feeding, it dies.

The use of a linearly increasing function of age to calculate the probability of feeding is based on data which shows a higher proportion of larvae feeding with age, i.e. a population estimate. It may be said that this is counterintuitive as far as individuals are concerned, that an individual would be less likely to feed as time goes on, due to the effects of starvation. It should be noted, however, that yolk-sac absorption has not yet taken place at the time of first-feeding readiness, and that the larva does not starve until this occurs. Yolk-sac absorption will occur sometime before the point of no return, and then the effects of starvation would probably operate. This is a difficult problem to parameterize properly, and for this preliminary model the effect is simplified through the use of the linearly increasing function.

Determination of the daily changes in depth of the yolk-sac larva is discussed in the section 'Biophysical coupling.'

\section{Feeding larval stage}

The probability of survival each day for feeding larvae is calculated in the same manner as described above in 'Egg stage, 'with $z_{\mathrm{f}}$ as the instantaneous daily mortality rate for feeding larvae.

A consumption-larval weight function slightly modified from Mackenzie et al. (1990) was further modified with a $Q_{10}$ function to account for the effect of temperature and adapted for walleye pollock:

$$
C=\left[10^{0.894 \log _{10}(W /-0.27}\right] \cdot\left[\mathrm{e}^{\left.\log _{10} / 10.0\right)\left(T-\tau_{\text {mat }}\right)}\right]
$$

where $C$ is daily consumption ( $\mu \mathrm{g}$ dry wt $\mathrm{d}^{-1}$ ); $Q_{10}=$ 2.0; and $T_{1 \mathrm{nit}}=4.5^{\circ} \mathrm{C}$.

A random deviate from a normal distribution with mean $C$ and variance $\mathrm{s}_{\mathrm{C}}^{2}=25.0 \mu \mathrm{g}$ dry wt $\mathrm{d}^{-1}$ was used as the daily consumption for an individual. The variance of the consumption rate was somewhat arbitrary, as there was no information on this parameter.
Feeding larval metabolic rates are based on the laboratory studies of Yamashita \& Bailey (1989), with a $Q_{10}$ modifier. Feeding metabolism (which includes resting metabolism plus the cost for specific dynamic action) is calculated as

$$
M_{\mathrm{fn}}=\left[0.00308 W^{0.9059}\right] \quad\left[e^{\left(\log Q_{10} / 10.0\right)\left[T-r_{\text {nit }}\right]}\right]
$$

Routine metabolism (which includes resting metabolism plus a cost for light-generated activity) is calculated as

$$
M_{\text {ro }}=\left[0.00253 W^{0.9699}\right] \cdot\left[\mathrm{e}^{\left(\log Q_{10} / 10.0\right)\left(T-T_{\text {int }} i\right.}\right]
$$

Total daily metabolic cost is calculated as

$$
M_{24}=\left(2.0 \cdot M_{\text {ro }} \cdot 16.0\right)+\left(M_{\mathrm{fn}} \cdot 8.0\right)
$$

where $M_{\mathrm{fn}}$ is feeding metabolism $\left(\mu \mathrm{l} \mathrm{O}_{2} \mathrm{~h}^{-1}\right), M_{\mathrm{ro}}$ is routine metabolism $\left(\mu l \mathrm{O}_{2} \mathrm{~h}^{-1}\right)$, and $M_{24}$ is $24 \mathrm{~h}$ metabolic cost $\left(\mu \mathrm{O}_{2} \mathrm{~d}^{-1}\right)$.

This assumes that the cost of active swimming while feeding is twice that of routine metabolism (Brett \& Groves 1979, Houde 1989). As mentioned by Houde (1989), this multiplier is commonly used, but may be conservative. It is also assumed that there are $16 \mathrm{~h}$ of daylight and $8 \mathrm{~h}$ of darkness (at $57^{\circ} \mathrm{N}$ latitude). Daily metabolic cost in $\mu l \mathrm{O}_{2} \mathrm{~d}^{-1}$ is converted to $\mu \mathrm{g} \mathrm{d}^{-1}$ as follows:

$$
R_{\mathrm{tot}}=M \cdot \gamma \beta
$$

where $R_{\text {tot }}$ is daily respiration rate ( $\mu \mathrm{g}$ dry wt $\mathrm{d}^{-1}$ ).

This uses the oxycaloric equivalent $(\gamma)$ of $0.00463 \mathrm{cal}$ $\mu \mathrm{O}_{2}$ (Brett \& Groves 1979), and a calorie to microgram conversion factor $(\beta)$ of $227.0 \mu \mathrm{g} \mathrm{cal}^{-1}$ (Theilacker \& Kimball 1984). Assimilation efficiency $(\alpha)$ is set equal to 0.8 , which is within the range of values cited by Webb (1978) and by Houde (1989) for marine fish larvae (when the temperature was extrapolated to $6.5^{\circ} \mathrm{C}$ ). Houde \& Shekter (1981), Checkley (1984) and Kiorboe et al. (1987) present evidence that both growth efficiency and assimilation efficiency varies with ration, however this factor has been neglected here for simplification and due to the lack of information on this subject for pollock.

The daily weight change of a larva is then calculated as

$$
W_{j+1}=W_{j}+\alpha \cdot C-R_{\mathrm{tot}}
$$

where $W_{j+1}$ is larval dry weight on day $j+1(\mu g), W_{l}$ is larval dry weight on day $j$, and $\alpha$ is assimilation efficiency. If there is a net gain in dry weight (i.e. if $\alpha C>R$ ), then the increase in SL is calculated as follows

(if SL is less than $7.0 \mathrm{~mm}$ )

$$
\begin{gathered}
I=10^{\left(\log _{10}(W)+0756\right) / 3.615} \\
\text { (Yamashita \& Bailey 1989) }
\end{gathered}
$$

(if SL is greater than or equal to $7.0 \mathrm{~mm}$ )

$$
\begin{aligned}
& l=10^{\left(\log _{10}(W)+0.486\right) / 3.395} \\
& (\text { Bailey \& Stehr 1986). }
\end{aligned}
$$


If there is no net gain in dry weight (i.e. if $\alpha \cdot C \leq R_{\mathrm{tol}}$ ), then SL stays the same. Note that feeding larvae cannot shrink in length, as can yolk-sac larvae. This is because ossification of the vertebral column prevents shrinkage. The depth of a feeding larva at each time step is predicted from the algorithms described in the next section. When the larva reaches the size at metamorphosis $\left(S_{M}=22 \mathrm{~mm} \mathrm{SL}\right)$ it is considered a juvenile and is not followed any longer in the simulation.

\section{BIOPHYSICAL COUPLING}

The coupling of hydrodynamic models and biological IBMs may be accomplished in several ways, a discussion of which is beyond the scope of this paper. In this section we describe the method used in this modeling effort. In Simulation 1 the biological and the physical models are run separately, with Lagrangian output from the hydrodynamic model driving processes in the biological model. For Simulations 2 and 3 a dynamic coupling was implemented. The dynamic approach allowed the addition of fish behavior which could affect the movement of the floats representing individuals.

The biological IBM and the physical SPEM model are dynamically coupled in the following manner (Fig. 2). First, the SPEM model is run with a particular physical forcing scenario (winds, fresh-water input and boundary conditions). The model generates output once per day which includes low-pass filtered (halfpower point $=36 \mathrm{~h}$ ) velocity vectors and environmental variables (e.g. temperature and salinity) at each grid point. The IBM is then run. Individual fish (or groups of fish) are assigned to 'floats' inserted into the physical model domain at the time and place where each egg is spawned. Once per hour $\left(\Delta t_{c}=1 \mathrm{~h}\right)$, the location, temperature and salinity are updated for each individual. Individual depth histories are required as current shear in the water column means that water at one depth may be moving in a different direction than water at another depth. Furthermore, water properties such as temperature or salinity vary with depth, so that the vertical, as well as the horizontal path taken by an individual will determine the physical environment

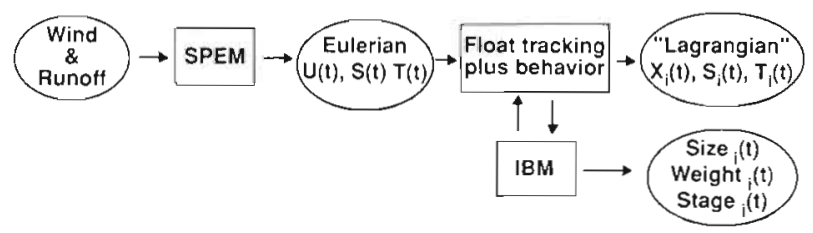

Fig. 2. Flow chart representing the coupling of the biological and physical models that it has been exposed to. This history will be integrated by an individual, resulting in a particular pattern of, for example, growth. The method of determination of the depth of an individual depends on its life stage, as vertical distribution or migration patterns differ depending on whether it is an egg, yolk-sac larva, or feeding larva.

In order to determine initial egg density, which is set equal to the water density at spawning depth (Kändler \& Tan 1965, Solemdal 1967, 1973), the output files from the SPEM run are called and a salinity at the location of each individual on the day of spawning is obtained. Water density is then calculated as in the physical model (Hermann \& Stabeno 1996):

$$
\rho_{w}=[0.824 \cdot S+999.843] \times 10^{-3}
$$

where $p_{w}$ is water density $\left(\mathrm{g} \mathrm{cm}^{-3}\right)$; and $S$ is salinity (ppt)

During the spring and summer seasons in this region, salinity is the most important factor determining density; temperature has only a very small effect

The density of an individual egg is assigned depending on its group (see 'Egg stage') which changes with development. As in Kendall \& Kim (1989), the terminal velocity of an egg in the vertical direction is calculated from the equation used by Sundby (1983) for Reynolds number $(\mathrm{Re})<0.5$

$$
w=g \cdot d^{2} \cdot \frac{\left(\rho_{e}-\rho_{w}\right)}{18.0 \cdot V}
$$

where $w$ is terminal vertical velocity $\left(\mathrm{cm} \mathrm{s}^{-1}\right) ; g$ is the gravitational constant $\left(g=980.0 \mathrm{~cm} \mathrm{~s}^{-2}\right) ; d$ is egg diameter $(\mathrm{cm}) ; \rho_{e}$ is egg density $\left(\mathrm{g} \mathrm{cm}^{-3}\right) ; v$ is the molecular viscosity of water $\left(v=0.161 \mathrm{~g} \mathrm{~cm}^{-1} \mathrm{~s}^{-1}\right)$; and Re is the Reynolds number $(\operatorname{Re}=w v / d)$.

The new depth of the egg after each time step is calculated as:

$$
z_{l+1}=z_{l}+w \cdot \Delta t_{c}
$$

where $z_{t+1}$ is depth of egg at new time step (m); $z_{t}$ is depth of egg at last time step (m); and $\Delta t_{c}$ is time step.

Yolk-sac larvae remain deep in the water column until first-feeding readiness, when they move upward in the water column at a speed of approximately $s s_{y s !}=0.3$ body lengths $\mathrm{s}^{-1}$ (B. Olla, M. O. Hatfield Marine Science Center, Newport, OR 97365, USA, pers. comm.) to a location in the upper 20 to $60 \mathrm{~m}$ of the water column.

In this model, feeding larvae begin diel migrations when they reach a length of $S_{\mathrm{dm}}=6 \mathrm{~mm}$ SL (Kendall et al. 1994). If larvae are less than $6 \mathrm{~mm}$, the change in depth is a function of swimspeed, which is a function of larval size. Mean swimming speed $\left(s s 1_{\mathrm{fd}}=0.1\right.$ body lengths $s^{-1}, B$. Olla pers. comm.) is used to generate a random deviate from a normal distribution. The direction of swimming (up or down) is also random. Note 
that horizontal swimming movement is not modeled here.

We modeled the pattern of vertical migration of feeding larvae greater than $6 \mathrm{~mm}$ based on the results of field studies (Kendall et al. 1987, 1994, Pritchett \& Haldorson 1989). Larvae are found at the deepest level during midday and at the shallowest level at dusk. They are found somewhat deeper at night than at dusk or at dawn. Diel migrations are assumed to be a response to light levels (Kendall et al. 1994), with movement toward a range of preferred light levels between $L_{\min }=6.0$ and $L_{\max }=13.0 \mu \mathrm{mol} \mathrm{m} \mathrm{m}^{-2} \mathrm{~s}^{-1}$. The minimum preferred light level was adjusted from that cited by Kendall et al. $\left(1994 ; 0.1 \mathrm{mmol} \mathrm{m}^{-2} \mathrm{~s}^{-1}\right)$ to produce a reasonable maximum depth of feeding larvae. Preferred light levels are used to calculate a preferred depth zone using Eqs. (18) and (19):

$$
\begin{aligned}
& z p_{\min }=\frac{\ln \left(L_{\max }\right)-\ln \left(R_{t}\right)}{-k} \\
& z p_{\max }=\frac{\ln \left(L_{\min }\right)-\ln \left(R_{t}\right)}{-k}
\end{aligned}
$$

where $z p_{\min }$ is minimum preferred depth $(\mathrm{m})_{i} z p_{\max }$ is maximum preferred depth $(\mathrm{m}) ; L_{\min }$ is minimum preferred light level $\left(6.0 \mu \mathrm{mol} \mathrm{m} \mathrm{m}^{-2} \mathrm{~s}^{-1}\right) ; L_{\max }$ is maximum preferred light level $\left(13.0 \mu \mathrm{mol} \mathrm{m} \mathrm{m}^{-2} \mathrm{~s}^{-1}\right) ; R_{t}$ is incident light at time $t\left(\mu \mathrm{mol} \mathrm{m}^{-2} \mathrm{~s}^{-1}\right)$; and $k$ is extinction coefficient $(k=0.16)$.

We assume an exponential decline in irradiance with depth, with incident light an average (sine function) dependent on time of day, measured just below the surface (i.e. not including reflected light). $k$ is a constant (R. Davis pers. Comm., Department of Oceanography, Dalhousie University, Halifax, Nova Scotia, Canada.

At each time step, the larva is moved in the vertical direction, with the distance travelled a function of swimming speed and time step size. The actual larval swimming speed during any one time step is a random variable with mean, ss $2_{\mathrm{td} l}=0.08$ body lengths $s^{-1}(\mathrm{~B}$. Olla pers. comm.), and variance, $s^{2}$ ssid: $=0.28$ The new position of the larva after each time step is checked to be sure that it is between $z p_{\min }$ and $z p_{\max }$, and that it is below $20 \mathrm{~m}$ (the mean depth assumed for the mixed layer, mld, as larvae are also assumed to avoid turbulence by remaining below the mixed layer; Kendall et al. 1994). If the larva's depth is less than $z p_{\text {min }}$ its depth is reset to $z p_{\min }$. If its depth is greater than $z p_{\max }$, the depth is reset to $z p_{\max }$. This resetting is meant to reflect the probable behavioral response of larvae to light levels. As light levels decrease toward dusk, the larva will move up in the water column. As $z p_{\min }$ and $z p_{\max }$ become less than the mixed layer depth at night, $z p_{\min }$ is set to $20 \mathrm{~m}$ (the mixed layer depth) and $z p_{\max }$ is reset to $20 \mathrm{~m}$ plus a random deviate from a normal distribution which has a mean equal to the standard deviation of the nighttime larval distribution $(\mathrm{SD}=3.65 \mathrm{~m}, \mathrm{~A}$. Kendall pers. comm., Alaska Fisheries Science Center, 7600 Sand Point Way, NE, Seattle, WA 98115). The larvae are thus distributed slightly deeper at night, as is seen in the field. As light levels increase at dawn, and the depth of the preferred light level deepens to below $20 \mathrm{~m}$, the larva again changes depth in response to light.

Note that since swimming speed increases with body size (Neilson \& Perry 1990), the distance moved during each time step increases and therefore the amplitude of the diel cycle increases for an individual as it grows. The model successfully reproduced the pattern of depth distribution that is observed in the egg, yolk-sac, and feeding larval period. The general pattern of depth by life history stage is shown in Fig. 3.

Once the depth of each individual is computed, its position and the values of temperature and salinity at its location are updated. This is accomplished via the float-tracking algorithm which interpolates a new position for an individual 5 times $\mathrm{h}^{-1}\left(\Delta t_{\mathrm{fta}}=0.2 \mathrm{~h}\right)$ using the velocity vectors from SPEM. Velocities are interpolated between grid points using linear interpolation in the horizontal direction, and Chebyshev polynomials in the vertical direction (Hedstrom 1994). The new location and the values of any physical variables at this location which are needed for driving biological processes are returned to the IBM. Values of temperature and salinity are averaged daily, and these averages used in the life-stage modules of the IBM (see above

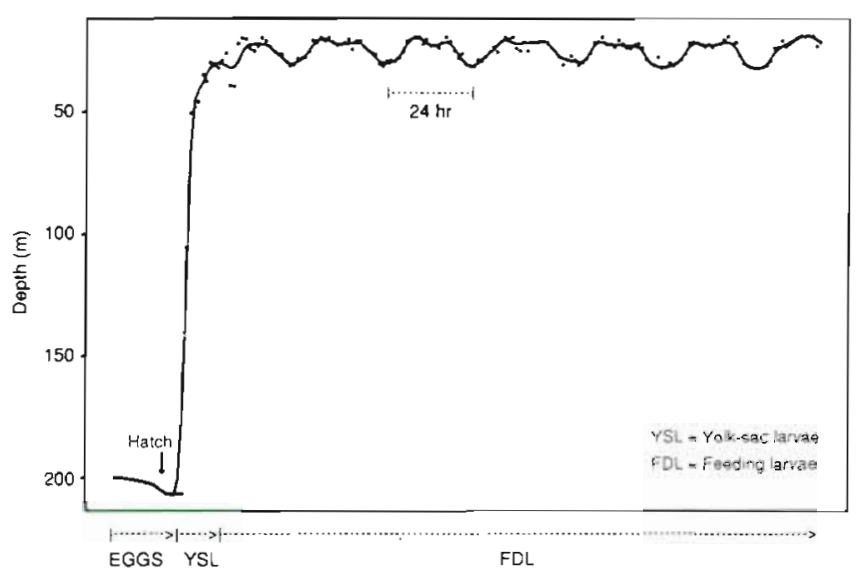

Fig. 3. Depth of a representative individual from spawning through the feeding larval stage. Note: Egg stage duration is about $2 \mathrm{wk}$, yolk-sac larval stage duration is about $1 \mathrm{wk}$. Diel cycle shown for feeding larvae. The dots show the daily position for the egg and yolk-sac stages and hourly positions for the feeding larval stage. The line represents a smoothed average. Note: Diel migration starts when FDL are $>6 \mathrm{~mm} \mathrm{SL}$ 
sections). The float-tracking algorithm produces a trajectory through space for each float over the model run.

\section{SIMULATIONS}

\section{Simulation 1}

The goal of Simulation 1 was to examine how the addition of spatial information, in the form of a Lagrangian time series of abiotic factors, affects the outcome of the IBM. In the first simulation, the hydrodynamic model was run once, with float tracking occurring simultaneously. The floats, whose initial positions correspond to initial organism concentrations in the model domain, were completely passive in this simulation. An array of 50 floats was tracked for $45 \mathrm{~d}\left(\right.$ dur $_{1}$ ) (DOY 105 to 150 ) directly within the hydrodynamic model described in Stabeno et al. (1995), driven by winds and buoyancy flux appropriate to 1989. Lagrangian time series of salinity are recorded for each float. These salinity values were converted to temperature using a linear temperaturesalinity relationship appropriate to the upper ocean at this locale and time.

An ensemble of $n_{1}=80000$ individuals was divided equally among the floats; thus, 1600 individuals utilize each of the 50 Lagrangian time series ('Lagrangian T' experiment). This is equivalent to 1600 independent runs of the biological model, each starting with the same spatial array of 50 individuals (the hydrodynamic model is deterministic). In the biological IBM, all 80000 individuals are tracked separately through the larval stage, until such time as each becomes a juvenile. The simulation begins on DOY 90; temperatures and locations at DOY 105 are used for the period of DOY 90 to 105. The physical model output begins at DOY 105 to allow more time for proper spinup of the wind-and buoyancy-driven velocity field (the physical spinup begins on DOY 1). Individuals which are still larvae beyond DOY 150 continue to utilize the temperature at DOY 150 until they reach the juvenile stage. Both length and weight of all individuals are updated at each time step in the simulation.

In contrast to the 'Lagrangian' experiment, a second set of 80000 individuals is subjected in the IBM to temperatures held constant at $\mathrm{T}=3^{\circ} \mathrm{C}$ ('constant $\mathrm{T}^{\prime}$ experiment). A third set is subjected to temperatures which increase linearly from $3^{\circ} \mathrm{C}$ to $6^{\circ} \mathrm{C}$ over the $45 \mathrm{~d}$ simulation period ('linear $\mathrm{T}^{\prime}$ experiment), as a proxy for seasonal warming in a spatially homogenous environment.

For the 'constant $\mathrm{T}$ ' case (Fig. 4a), individuals exhibit a normal distribution of lengths, with minor vari- ations, at DOY 110, 140 and 160. Length increases exponentially through time as expected. Similarly, in the 'linear $\mathrm{T}$ ' case (Fig. 4b), the distribution is still quasinormal, although the general rate of development is faster than the constant $\mathrm{T}$ case, and all individuals have either died or passed into the juvenile stage before DOY 160. In contrast, the 'Lagrangian T' case (Fig. 4C) exhibits a significantly different pattern. By DOY 110, the initial normal distribution becomes skewed, with a preponderance of individuals at the low end of the range of lengths (Fig. 4c). By DOY 140 , lengths of survivors evolve into a bimodal distribution. By DOY 160, lengths of survivors are strikingly fragmented into 2 groups. Bimodal length distributions have been seen in young walleye pollock in the Gulf of Alaska (M. Wilson, Alaska Fisheries Science Center, 7600 Sand Point Way NE, Seattle, WA 98115, pers. comm.). These patterns arise from the variation in environmental conditions experienced by these larvae. Fig. 5 shows the Lagrangian time series of temperature for a subsample of the floats. Some of the records remain nearly constant, others exhibit trends to higher or lower values, and others vary in an erratic manner, possibly as a result of their being advected in and out of the mesoscale features captured by the physical simulation.

The spatial tracking of individuals allows us to map weights, lengths and temperatures as a function of space and time. Fig. 6 illustrates the positions of larvae and temperatures at those locations at DOY 105. The larval habitat is coldest near the coast (due to the input of cold, fresh waters at the coast in the physical model) and warmer further away from the coast. The absence of any individuals in the larval stage at this date near the coast is due to the lower temperatures there, and the resulting slower development times in the egg stage. High mortality rates in the egg stage deplete the stock of potential larvae at this location, eliminating the stock of larvae there by DOY 105. The pattern of weights of surviving larvae shows generally heavier individuals in the eastern part of the sea valley and shelf, and lighter individuals to the north and west by DOY 150 (Fig. 7). Note, however, that considerable patchiness exists, with heavy individuals juxtaposed with much lighter ones at some locations. A number of individuals were advected to the south and east of the sea valley and Kodiak Island. This is not something which is commonly seen in field data and was determined to be an artifact of the crude bathymetric dataset employed by this early model. A finer bathymetric dataset (Hermann \& Stabeno 1996) was used for all subsequent simulations, to eliminate this bias. A plot of larval weights versus accumulated degree days at DOY 150 (Fig. 8) reveals that much of the variance in weights among 

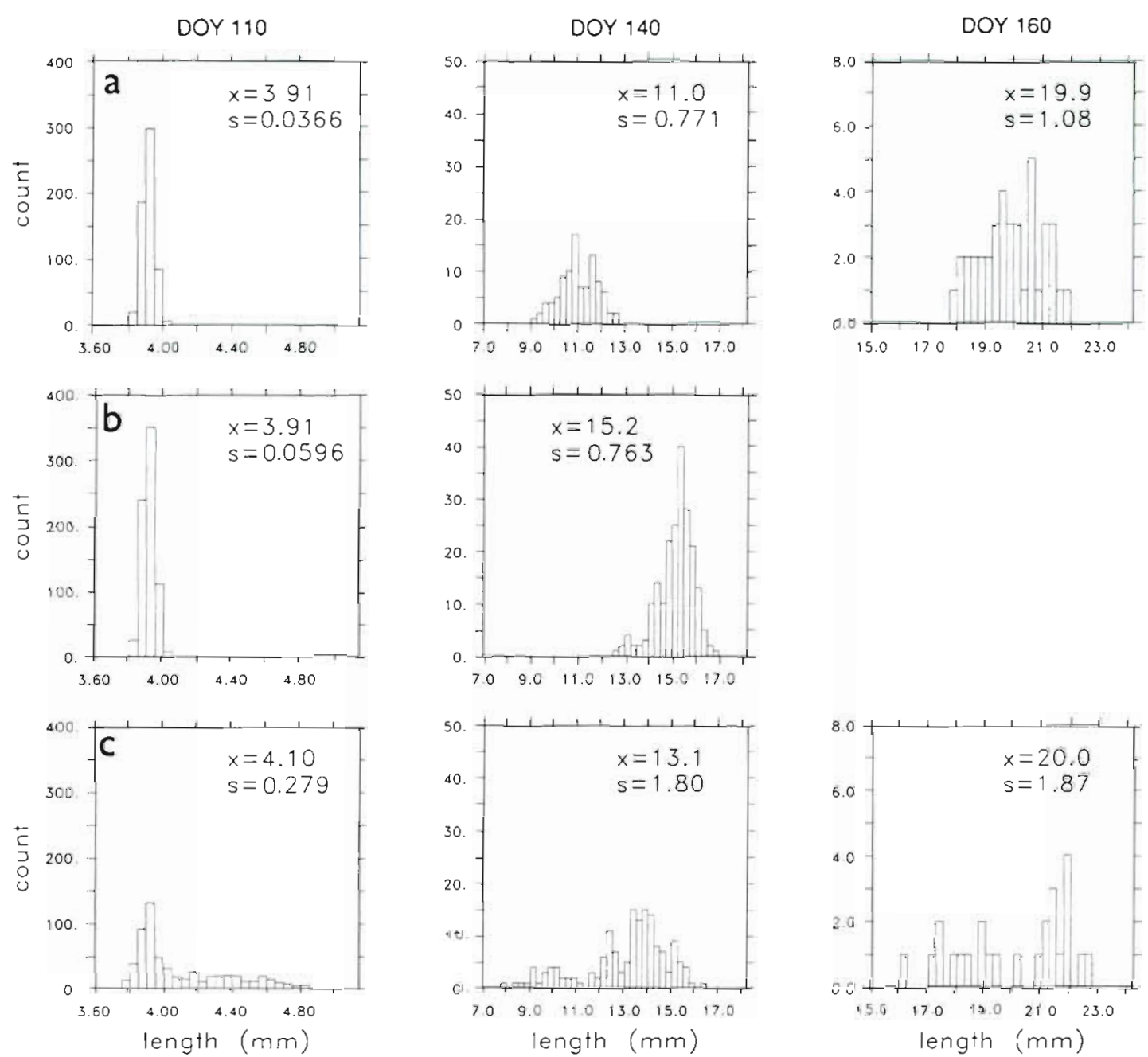

Fig. 4. Length distributions of the larval stages from Simulation 1 'Count' refers to the number of individuals represented by each bar. (a) 'Constant $T^{\prime}$ case; (b) 'Linear $T$ ' case (c) 'Lagrangian $T^{\prime}$ ' case

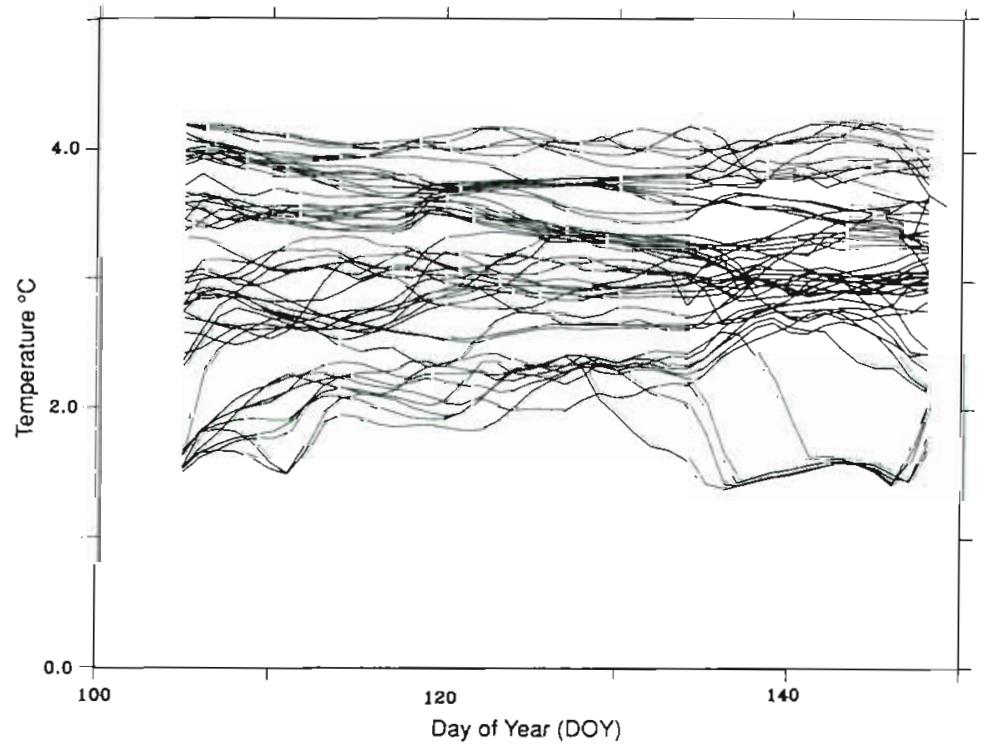

Fig. 5. Lagrangian time series of temperature following 25 of the floats tracked by the hydrodynamic model. Floats are initially released in a square pattern at $40 \mathrm{~m}$ depth, at the southwestern end of Shelikof Strait between Kodiak Island and mainland Alaska 


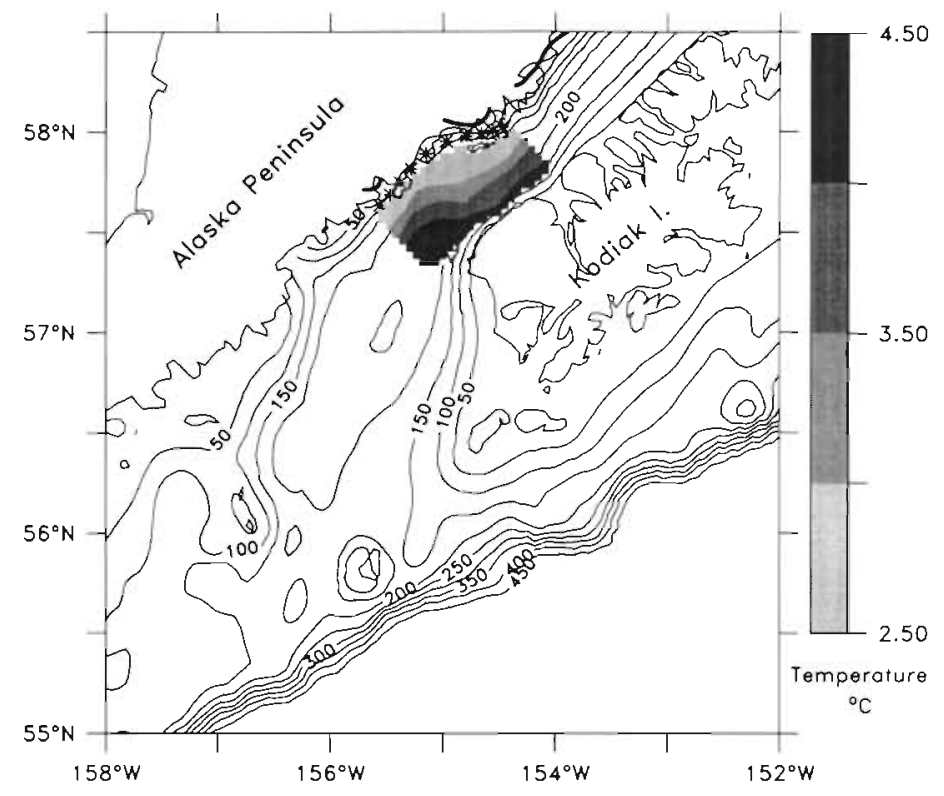

Fig. 6. Temperatures of tracked floats at DOY 105. Temperatures are represented in greyscale; *: position of a float associated with no living individuals (that is, all individuals using temperature series from that float have died)

individuals can be explained by the integrated temperature history. Note that while the integrated Lagrangian temperatures exhibit a range of values, they do not exhibit a simple bimodal pattern of 'warm' versus 'cold' individuals. Hence, the ultimate bimodal pattern must be attributed to both the deterministic temperature factors and the random mortality, life-stage transitions, and feeding in the probabilistic IBM.

\section{Simulation 2}

The goal of Simulation 2 was to test whether the addition of complex algorithms to predict the depth of individual fish (i.e. those described in the section on 'Biophysical coupling') caused significant changes in the horizontal trajectories of individuals when compared to the trajectories derived via the use of a simpler scheme to predict depth (an average depth for each stage for all individuals). These complex depth prediction algorithms are a major component of the method that we have used to couple the biological and the physical models. We also wanted to examine whether the trajectories for particular individuals resulting from changes in vertical location yielded significantly different growth histories, due to the different histories of exposure to temperature or salinity, versus those resulting from use of an average depth for each life stage. In this simulation, temperature affects egg development rate, yolk-sac stage duration, and consumption and metabolic rates in the feeding larval stage, and salinity affects egg density and vertical movement.

Two model runs were carried out. For both simulations, the hydrodynamic model was run once, and the velocity, temperature and salinity output at each model gridpoint was stored every 15 d. A $10 \times 10$ grid of spawning locations was set up (Fig. 9) and used for both runs. Thirty floats (individuals) were released from each grid point on DOY 90 at $200 \mathrm{~m}$ depth for a total of $n_{2}=3000$ individuals per run. This is equivalent to 30 runs of 100 individuals. The duration of Simulation 2 was $140 \mathrm{~d}\left(\mathrm{dur}_{2}\right)$. The 2 model runs were as follows. For the null model, eggs were constrained to remain at $\operatorname{dep}_{\mathrm{e}}=200 \mathrm{~m}$, yolk-sac larvae at depysl $=100 \mathrm{~m}$ and feeding larvae at $\operatorname{dep}_{\mathrm{fdl}}=40 \mathrm{~m}$. These are average depths derived from field observations (Kendall et al. 1994). For the alternative model, vertical location in the water column at each time step varied as described above ('Biophysical coupling'). Mortalities for these simulations were set to zero $\left(z_{\mathrm{e}}=z_{\mathrm{y}}=z_{\mathrm{f}}=0\right)$ so that smaller numbers of floats could be followed. Simulations were run for 140 d, from DOY 92 to 232

Fig 10a, b shows the trajectories of 2 floats, one released from either end of the southwestern-most row of the grid, for each run. The floats do not follow the same

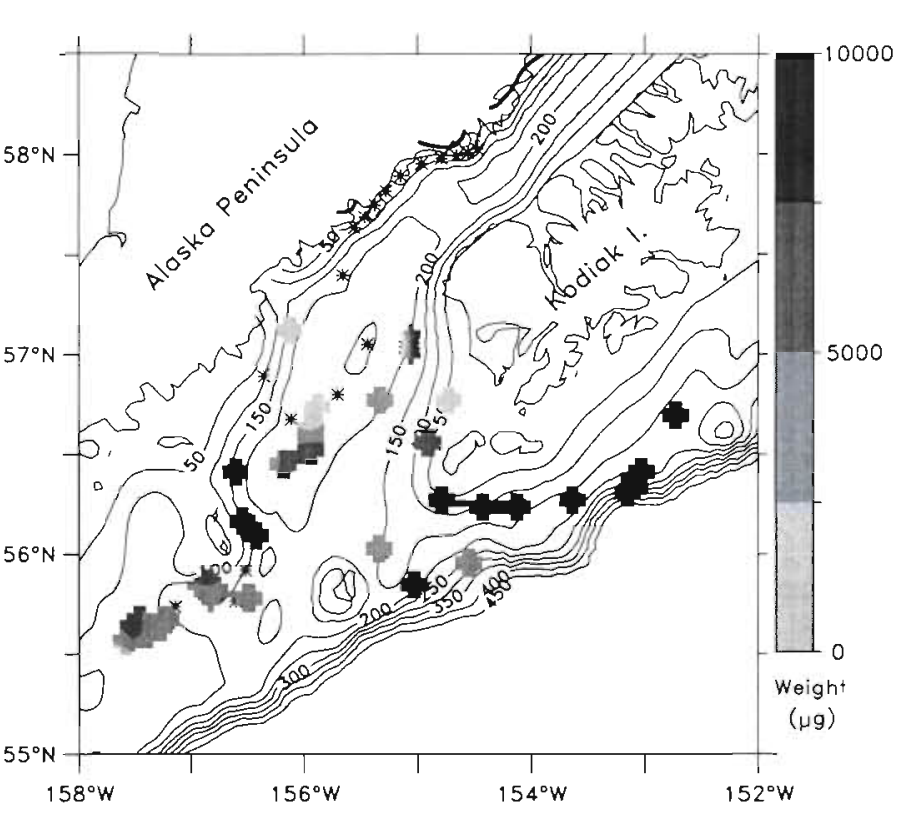

Fig. 7. Average weights for living individuals associated with each of the tracked floats at DOY 150. Mean weights are represented in greyscale; *: all dead individuals 


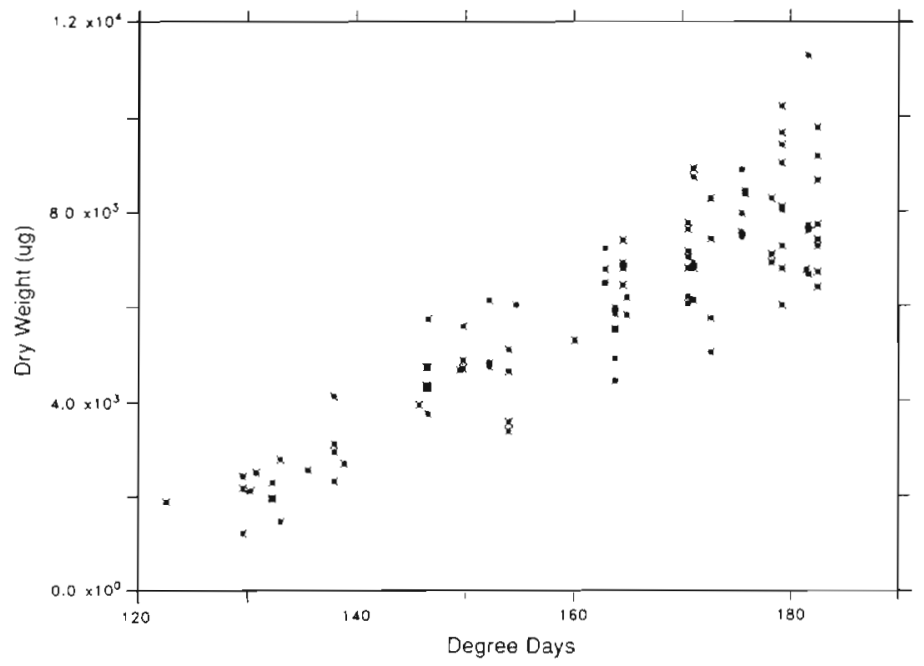

Fig. 8. Scatter plot of individual weights at DOY 150, versus degree days accumulated by each individual at DOY 150

track, and the endpoints of the float tracks are not in the same positions for the null and the alternative models. In order to test whether the trajectories are different for each depth algorithm we decided to use latitude and longitude on DOY 149 as a representative bivariate measure. Location on DOY 149 was chosen because it is the day before the first larva metamorphosed into the juvenile stage (i.e. the last day in which all larvae are still in the model). A multivariate ANOVA was done which included depth algorithm (null or alternative), initial position and the interaction between depth algorithm and initial position as factors and latitude and longitude on DOY 149 as the dependent variables. This analysis indicated a significant interaction effect (MANOVA, $p<0.001)$. We therefore ran separate MANOVAs for each initial location, with the depth algorithm as the only factor We found that the effect of the depth algorithm was significant for each initial position (MANOVA, $p<0.001$ for all tests). We interpret this to mean that the divergence among trajectories of individuals due to the effect of the depth algorithm varies with the starting location, but that it is significant overall.

It seems reasonable to conclude that varying vertical location has an important effect on the subsequent horizontal position of an individual, and that correct advection of individuals through space using this model is dependent on specifying the depth of individuals in a manner which reflects what is known about their true vertical distribution and migration rather than using a simplified scheme.

We examined whether the addition of vertical migration, as in the alternative model, resulted in any differences in growth rates, dates of transitions or other individual attributes between the 2 model runs. Such differences would be due to different temperature histories resulting from the differing vertical and horizontal trajectories. When a linear model is fit to the lengthage relationship (with length square-root transformed to linearize the data) for modeled larvae, there is a significant difference between the null model (Fig. 11a) and the alternative model (Fig. 11b) (ANCOVA, $p<0.001$ ). The mean length on DOY 149 was larger and the standard deviation of length on DOY 149 was less variable for the null model (Fig. 11c) than for the alternative model (Fig. 11d). The date on which first feeding occurred (i.e. the transition from the yolk-sac larval to the feeding larval stage) was earlier in the null model ( $t$-test, $p<0.001)$, as was the date at which metamorphosis from the feeding larval stage to the juvenile stage occurred ( $t$-test, p < $0.01)$ It is apparent from these statistics that growth and other life history characteristics of young pollock were significantly affected by the choice of depth algorithm.

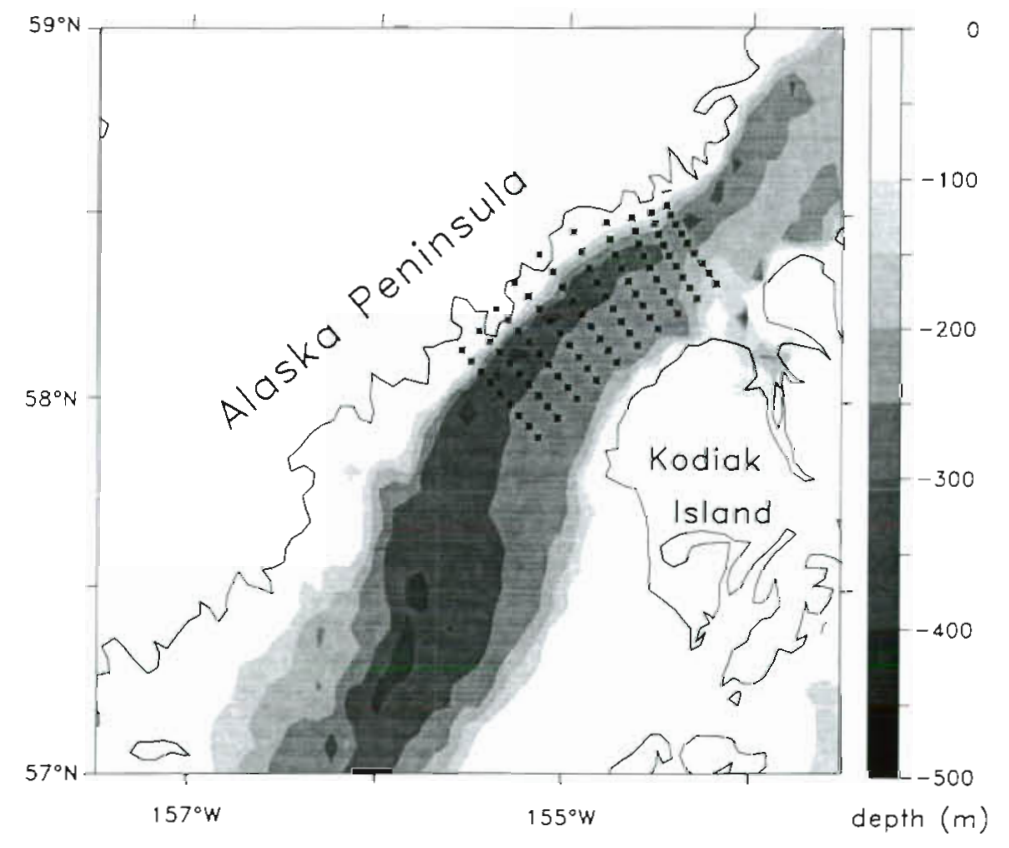

Fig. 9. Grid of spawning locations for the Simulation 2 model runs. The locations of the points closest to land are offshore of the landward boundary of the numerical model, which is smoothed compared to the actual coastline shown in this figure 

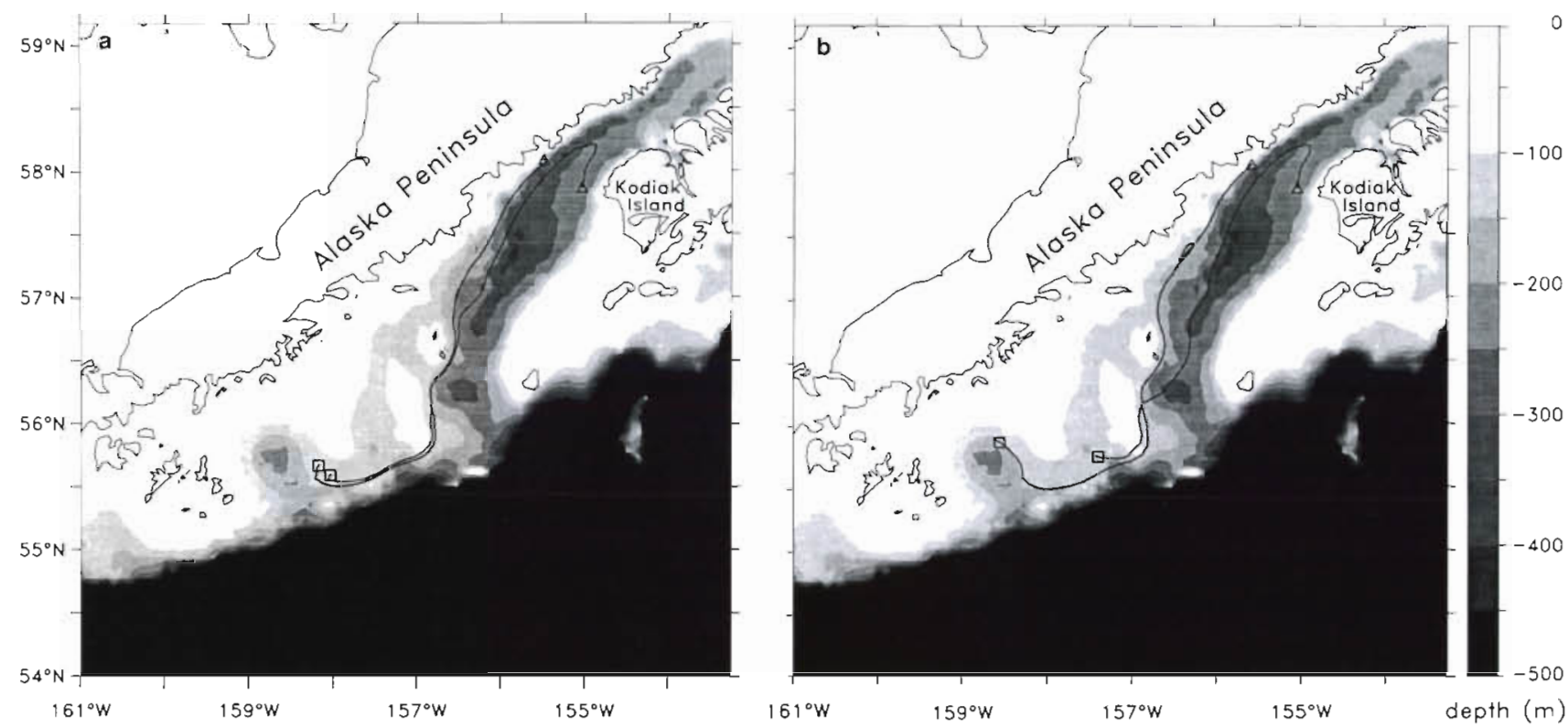

Fig. 10. Trajectories of (a) 2 representative floats from the Simulation 2 model run which uses the null model (i.e. average depths for each stage), (b) of same 2 floats as in Fig. 14a from the Simulation 2 model run which uses the alternative model; that is, the vertical movement and migration algorithms described in the text under 'Biophysical coupling'
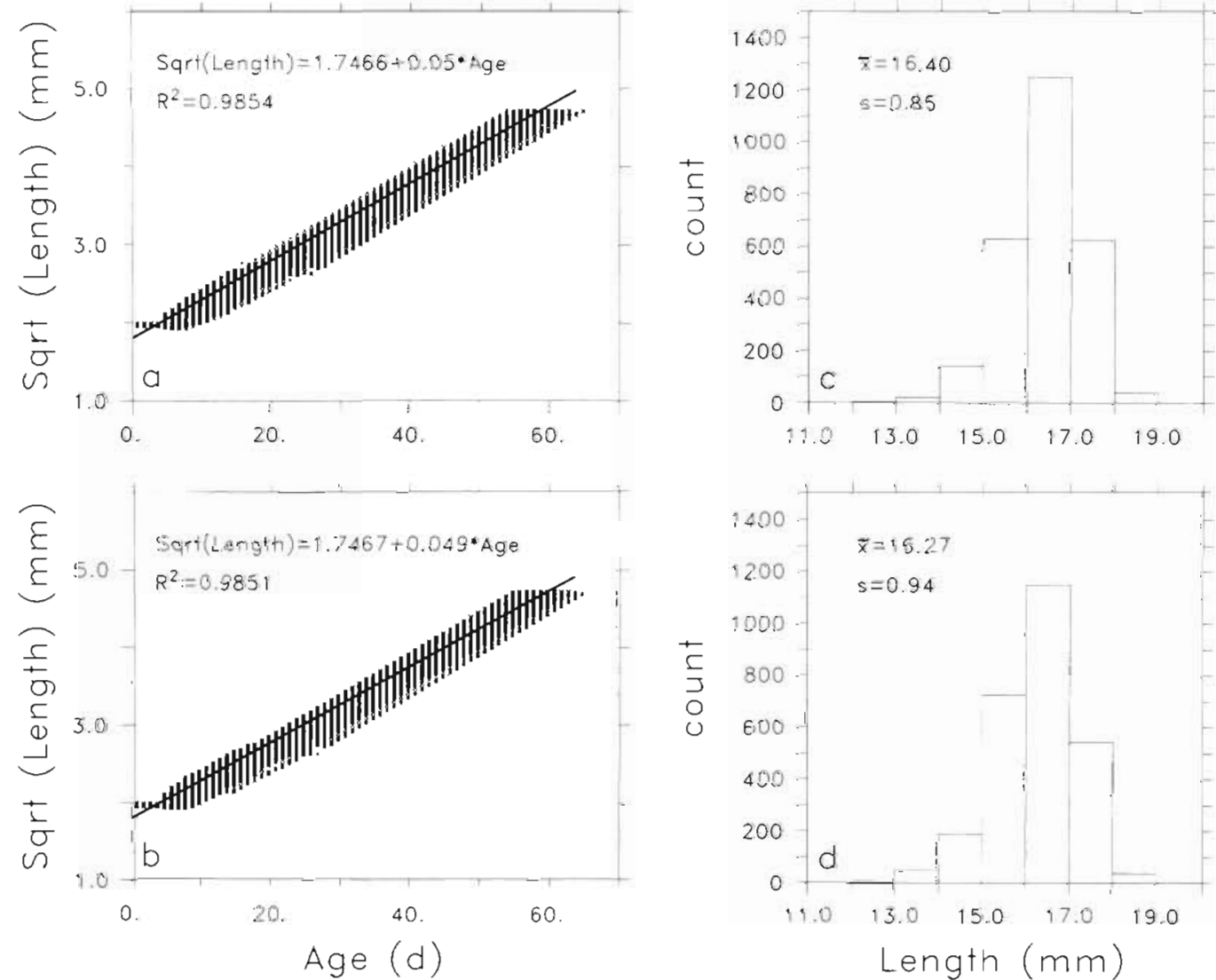

Fig. 11. (a) Length-age relationship for larvae from the null model, Simulation 2. Line represents the fitted linear equation. (b) Length distribution of larvae from the alternative model, Simulation 2. (c) Length-age relationship for larvae from the null model, Simulation 2. Line represents the fitted linear equation. (d) Length distribution of larvae from the alternative model, Simulation 2 

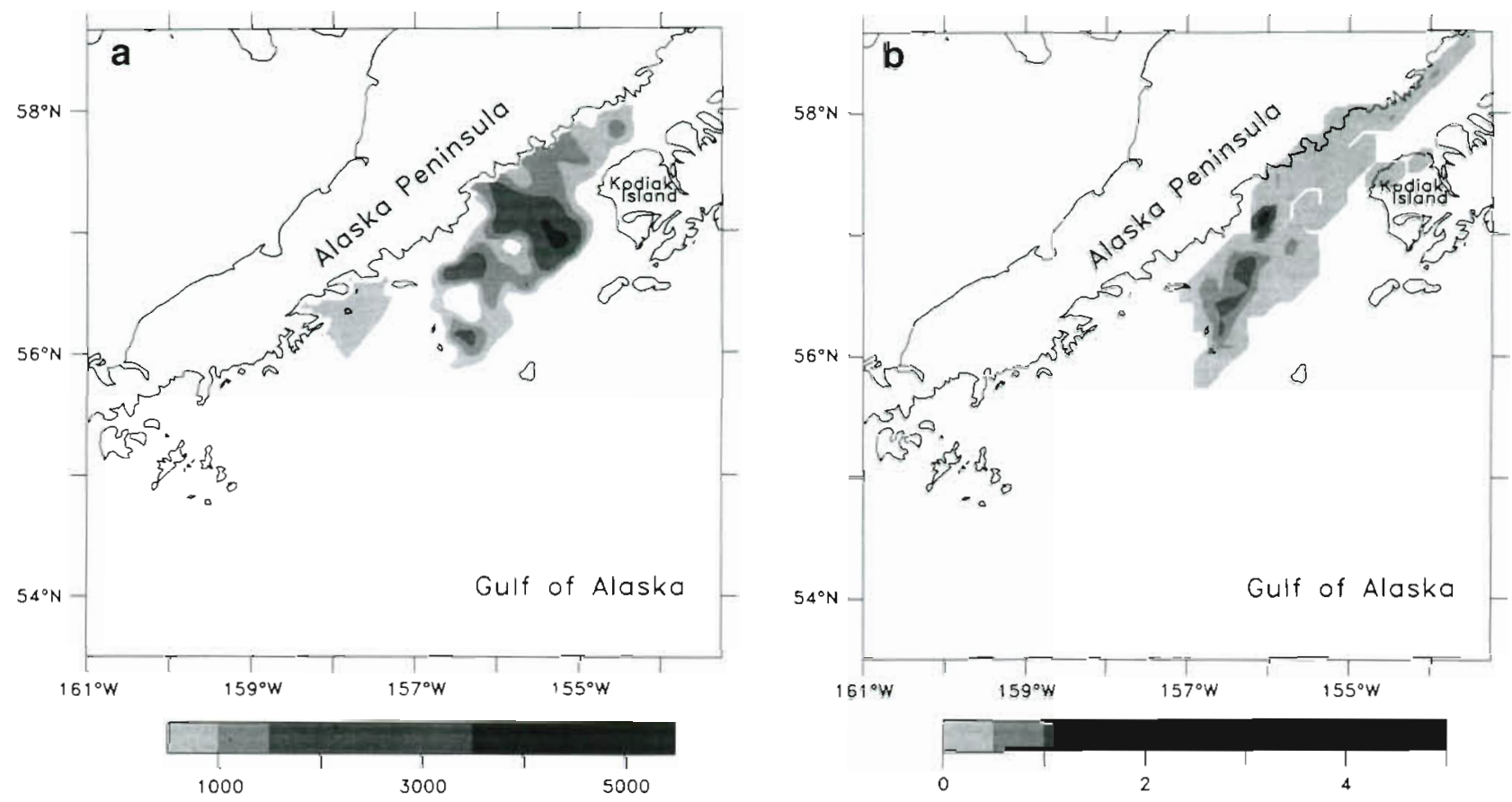

Fig. 12. (a) Measured abundance of larval walleye pollock between May 9 and 16, 1989. (b) Abundance of larvae from Simulation 3 model run for May 10, 1989. Gray scale represents relative larval densities

\section{Simulation 3}

We examined the ability of the model with complex depth algorithms ('Biophysical coupling') to predict the distribution of various life stages for a particular year. The physical model was forced with wind and fresh water input conditions present in 1989, and the IBM run with the resulting velocity fields. The IBM was seeded with $n_{3}=1600$ individuals at 50 grid points ( 32 individuals per grid point). All 1600 fish were followed individually for $70 \mathrm{~d}$ $\left(\right.$ dur $\left._{3}\right)$, hence each has a unique spatial trajectory. This configuration is equivalent to 32 independent trials of the model with the same grid of 50 initial locations for each run. Eggs were released at $200 \mathrm{~m}$ depth on DOY 92. Mortalities for each life stage were set to zero to reduce the need to follow many individuals. Fig. 12a shows the observed larval distribution between May 9, 1989 and May 16, 1989, as measured by a National Marine Fisheries Service ichthyoplankton survey (Savage 1990). Fig. 12b shows the modeled distribution of larvae on May 10, 1989. Although details differ, these 2 plots appear similar in that the highest concentrations of larvae are found near Sutwik Island and in the middle of the sea valley in both, although the highest measured distribution was somewhat farther offshore. The modeled distribution also shows a similar degree of patchiness as the measured distribution.
Fig. 13a, b shows the measured versus modeled larval distributions near the end of May 1989. The distributions again appear similar, with high concentrations near both Sutwik and the Semidi Islands, and similar patchiness of distribution. Stabeno et al. (1996) indicate that estimates of Lloyd's index of patchiness for larvae during May ranges for the most part between 5.0 and 7.0 , with a few higher values. The Lloyd's index from model results shows a very similar mean $(-5.0)$ for this time period. Figs. $12 \& 13$ show that, in a qualitative sense, the coupled biophysical model is capable of hindcasting larval distributions to a reasonable degree of precision. This hindcasting is not perfect due to the difficulty of capturing all of the true mesoscale variability of currents in the physical model, as discussed in Stabeno \& Hermann (1996).

Fig. $14 a-h$ shows a series of output from the biophysical model. These are plots of individual fish locations from the above-described simulation for DOY 90 to 160 at $10 \mathrm{~d}$ intervals. At the beginning of the simulation on DOY 90 the eggs are released in Shelikof Strait. The egg mass follows the bottom topography and moves to the southwest (downstream). As they move downstream the eggs disperse, hatch into yolksac larvae and then feeding larvae. This series of distribution plots reproduces the conceptual model of egg and larval transport (Fig. 15) which has been derived from field observations. 

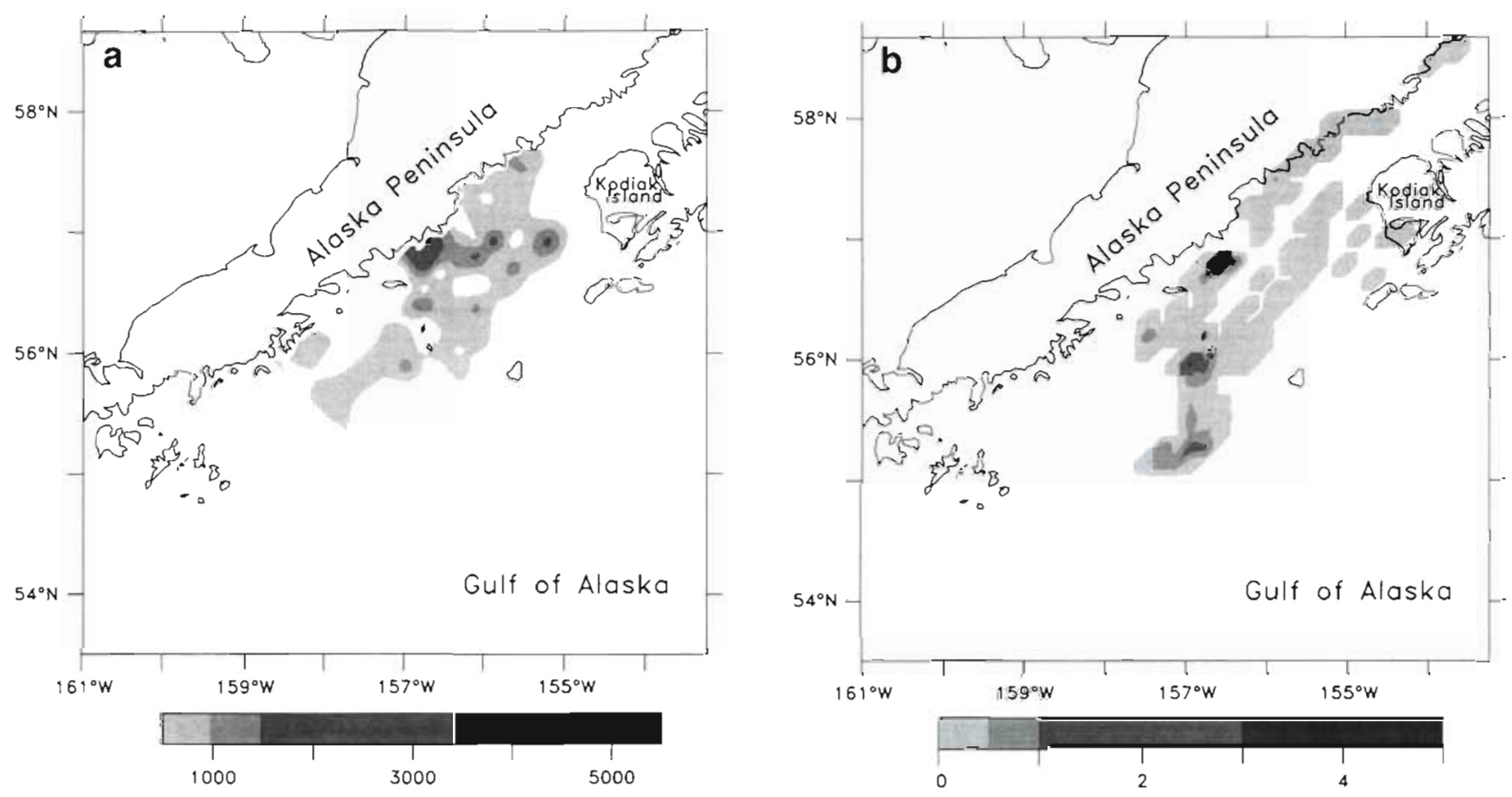

Fig. 13. (a) Measured abundance of larval walleye pollock between May 29 and June 5, 1989. (b) Abundance of larvae from Simulation 3 model run for May 30, 1989. Gray scale represents relative larval densities

\section{DISCUSSION}

This paper presents results from a coupled biophysical model, and several simulations we have performed to illustrate specific points related to model development. The overall goal of the modeling effort is to (eventually) examine recruitment processes. In this preliminary stage, however, we have attempted primarily to answer the following questions: (1) how sensitive are growth characteristics and other attributes of larval pollock to spatial differences in temperature acting on individuals, and how do these differences affect population-level distributions of attributes; (2) how sophisticated does the prediction of the depth of individuals need to be in such a coupled model, in order to correctly predict horizontal advection; and (3) how qualitatively similar do modeled and observed distributions for the various life stages appear to be?

It is appropriate to keep in mind that in the biological IBM, the effects of abiotic factors on the attributes of young fish are simplified. With the addition of biotic factors such as predators and prey, with more complexity in the abiotic effects (such as a varying $Q_{10}$ ), and with mortality due to starvation and predation added, patterns observed in the model output will undoubtedly be somewhat different in detail from what we observe in the initial simulations described in this paper. Only after this development is complete will we be able to quantitatively compare modeled versus observed output and distributions, and examine our hypotheses about recruitment.

Simulation 1 illustrates how the inclusion of even rudimentary spatial information can radically alter the outcome of the IBM. Even a simple example, using the Lagrangian approach without behavioral feedback, yields strikingly different distributions of population attributes than the same model with no spatial information. In particular, the added Lagrangian information yields a bimodal distribution of weights and lengths of larval fish, as opposed to a unimodal normal distribution in the case with no spatial tracking. The Lagrangian method produces a patchy distribution of larvae, with population variance in weights and lengths apparently due to both individual temperature histories and random mortality, life-stage transitions and feeding factors.

Simulation 2 shows how the inclusion of a complex algorithm for vertical movement of individuals can significantly alter their horizontal advection and growth relative to a scheme where depths for each life stage are fixed. Vertical locomotion will, over time, significantly alter the spatial paths and the life history of individuals relative to a scheme where depths are constant. Although unnecessary complications are to be avoided in modeling, there are compelling arguments for the inclusion of the vertical migration subroutine in the coupled model versus using a more simplified approach to determining individual depths. Such rea- 

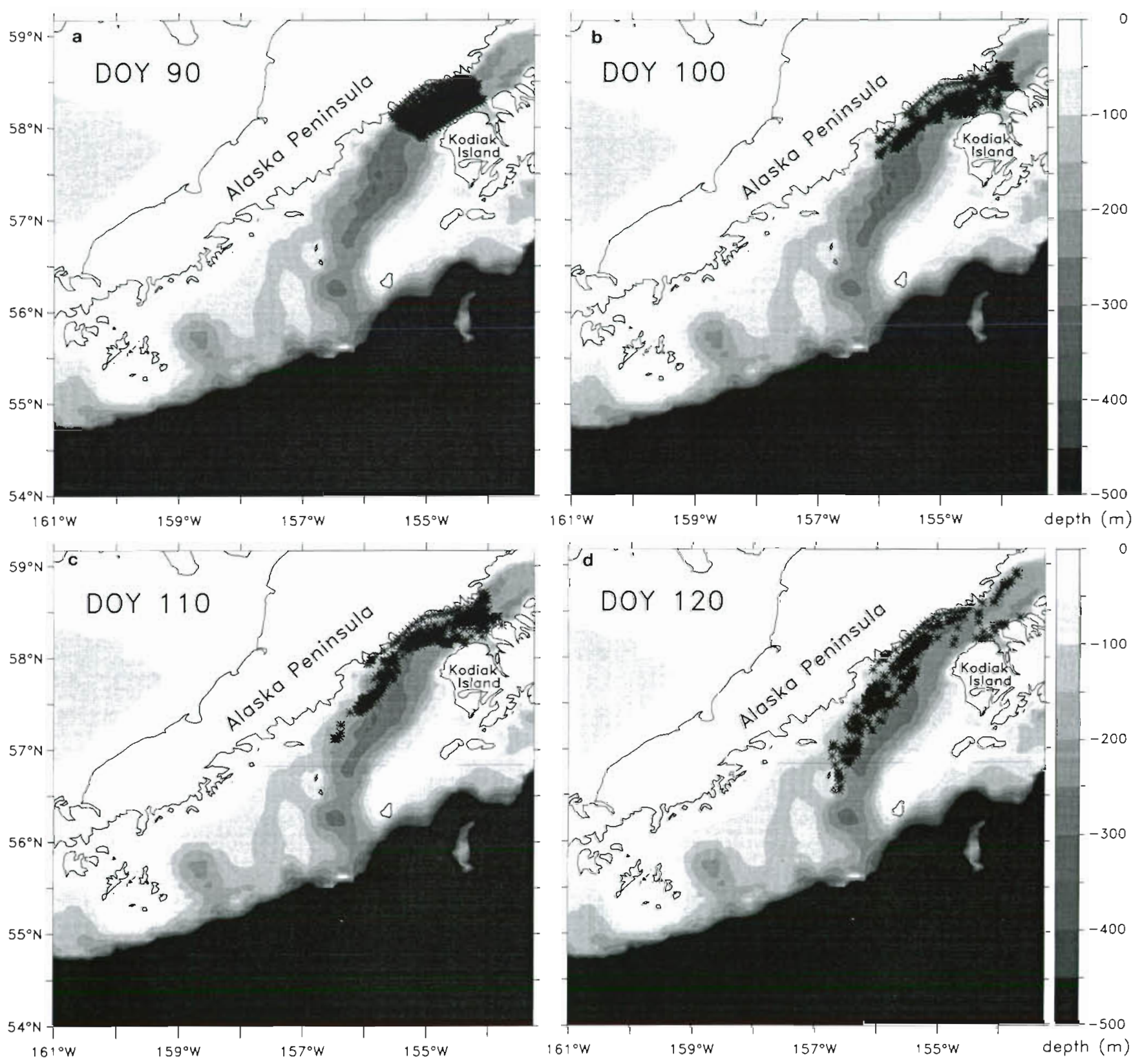

Fig. 14a-h (facing page and above). Plots of modeled egg and larval walleye pollock distributions for DOY 90 (March 31 ) through DOY 140 (May 20) from Simulation 3 model run

sons include that we know that complex vertical movement occurs, it appears to have an important effect on the horizontal trajectory of an individual, and i.t has a significant effect on growth and other attributes of individuals.

Page et al. (1989) suggest that the vertical distribution of pelagic organisms plays an important role in determining the rate and direction of their horizontal displacement and their interaction with prey and predators.' Hjort $(1914,1926)$ was the first to suggest that transport to favorable nursery areas could be important in the survival of early life stages of marine fish which spawn pelagic eggs. Knowledge of advection patterns of eggs and larvae from the spawning area to the nursery grounds is therefore important to recruitment studies, especially in highly advective systems, like Shelik of Strait. Transport or retention patterns can also determine the overlap of larvae with their predators and prey, and expose larvae to varying suites of environmental factors, thereby affecting mortality and growth rates (Frank \& Leggett 1982, Leggett et al. 1984, DeBlois \& Leggett 1993). The distribution 

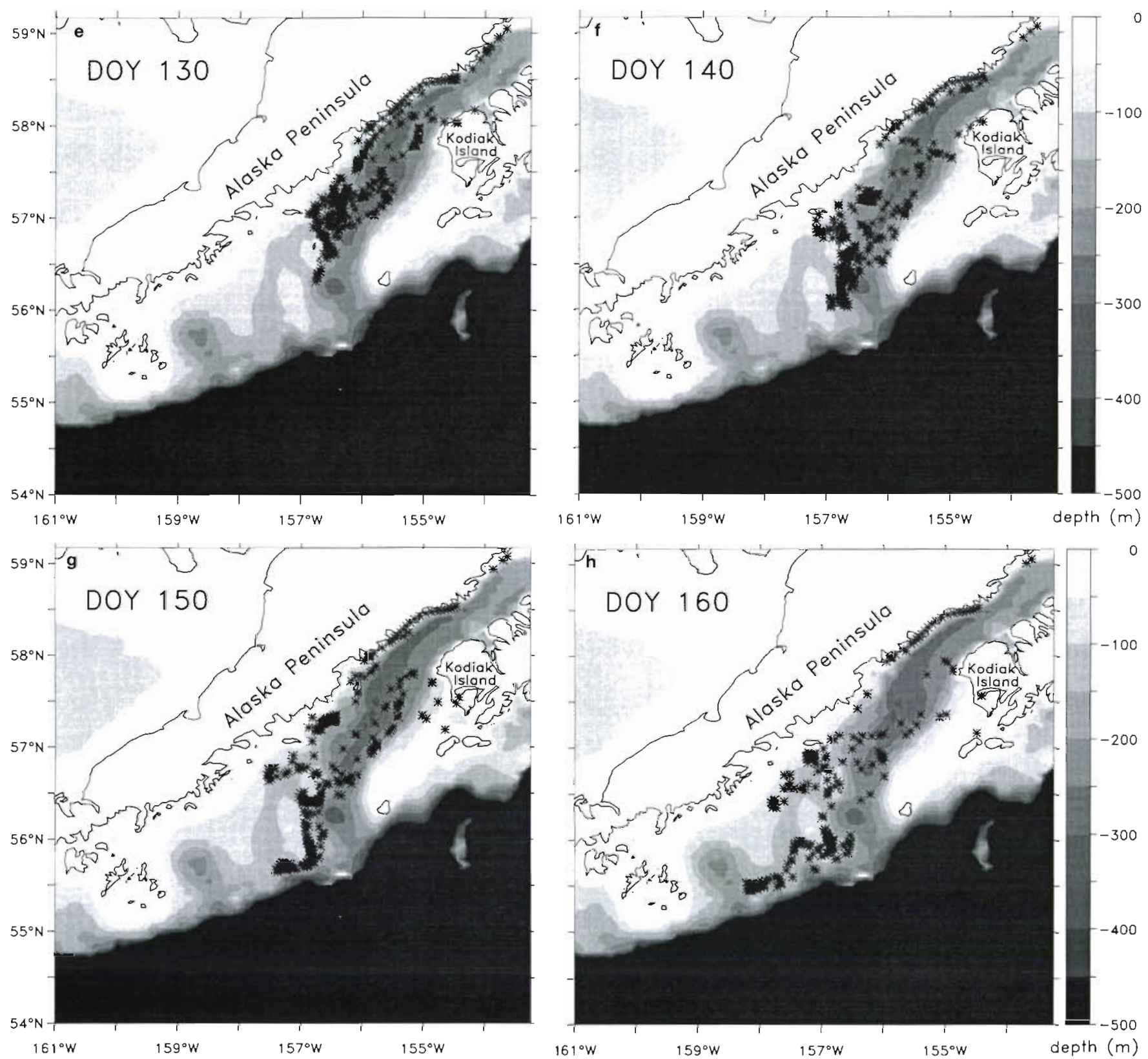

and abundance of eggs and larvae as these change through time and space depend both on biological characteristics (such as spawning intensities with time and place, developmental periods, buoyancy of eggs and larvae, existence of predators and food organisms), as well as interactions with environmental variables (e.g. current velocities and directions, water temperatures and water densities).

Walleye pollock eggs are spawned and develop at depths of 150 to $250 \mathrm{~m}$, and later the larvae reside in the upper layers (20 to $50 \mathrm{~m}$ ) (Kendall et al. 1987). During the $2 \mathrm{wk}$ (at $5^{\circ} \mathrm{C}$ ) incubation, eggs exhibit vertical movement in the water column due to changes in the

egg's density during development, and movement toward the depth where they are neutrally buoyant. Kendall \& Kim (1989) developed a model of distribution of eggs in the water column based on these changes in buoyancy and assumed differences in water density at depth. Their model could not, however, predict differences in distribution of eggs of different stages in the water column, as it did not take into account the variability of water density horizontally that can arise due to the highly variable current system in Shelikof Strait, and interannual differences in this factor. Neither did Kendall \& Kim's model take into account the likelihood that the initial density of eggs is 


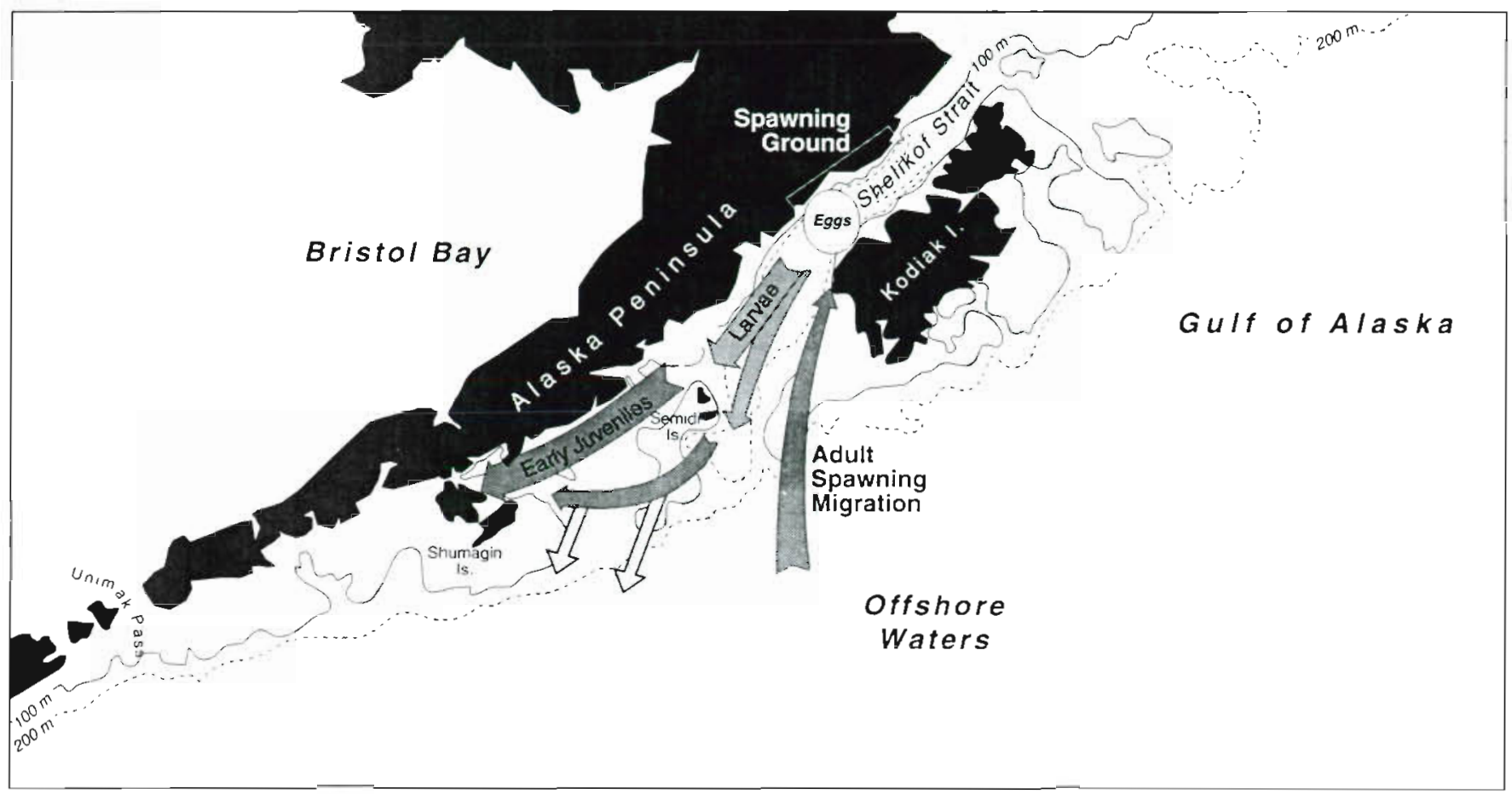

Fig. 15. Conceptual life history of Gulf of Alaska walleye pollock showing the spawning area in Shelikof Strait, the downstream movement of eggs, larvae and juveniles, and the return migration of spawning adults

related to the depth at which females spawn due to uptake of surrounding water with hydration and fertilization of the eggs.

Prior to first feeding, larvae move quickly from depths of 150 to $200 \mathrm{~m}$ to the upper parts of the water column (Kendall et al. 1994). This movement is probably due to negative geotaxis or barotaxis since there is insufficient light to induce phototaxis at the hatching depth (Olla \& Davis 1990). Kendall et al. (1994) propose that movement to a preferred light level may be the controlling factor in diel migrations of larval pollock and that 'this cycle may allow larvae to maximize their daily feeding period by being shallower in the early morning when visual feeding is possible as the sun comes up than during midday, and by rising to such depths as light fades in the evening.' Lab studies indicate that larvae avoid bright light (possibly to avoid visual feeding predators) and demonstrate negative geotaxis or barotaxis during low light levels, which could produce this cycle. Diel migration starts when larvae are $>6 \mathrm{~mm}$ in length (Kendall et al. 1994).

A complex suite of factors may drive vertical migration (Appenzeller \& Leggett 1995). The daytime depths of larvae coincide with the depths of maximum concentration of copepod nauplii, the main food source of pollock larvae. Temperature, Iater in May when the water column is thermally stratified, may be used as a cue to stay in the upper parts of the water column. Turbulence in the water column has been hypothesized to have both positive effects [increased encounters with prey (Rothschild \& Osborn 1988), enhanced primary production due to the infusion of nutrients from below the photic zone] and negative effects [dilution of vertically enriched layers of prey to levels below successful feeding threshholds, reduced naupliar production (Lasker 1978), and reduced capture success (MacKenzie et al. 1994)]. In the laboratory, larval pollock avoid turbulence (Olla \& Davis 1990) although it is difficult to compare levels of turbulence induced in the laboratory with those seen in the field. Kendall et al. (1994) found that larvae were found deeper during periods of high winds, and that larvae were most often located near the base of the mixed layer.

By explicitly including only light and the location of the mixed layer as external factors regulating larval depth, we are neglecting the possible modification of the diel migration cycle by other factors, such as prey distribution and patchiness, temperature, feeding motivation, bioenergetics, or predator avoidance. Neilson \& Perry (1990) state that 'combinations of external stimuli may act to modify or override the dominant influence of light intensity.' Prey movements, for example, are likely to have an influence; however, prey distributions are probably responding directly to 
light (Neilson \& Perry 1990, Kendall et al. 1994), therefore light may be a good proxy for prey effects. We know very little about direct effects of predator avoidance on vertical movement in the field. We are also ignoring arguments for energetic motivations for diel migration (Neilson \& Perry 1990), as they seem unlikely to be controlling the cycle.

Eventually, a dynamic mixed layer will be included in the hydrodynamic model as changes in mixed layer depth may significantly affect the vertical location of larvae. Another process which may become necessary to include in the model are the specific effects of turbulence on larvae (as discussed above). Also, as noted above, incident light is now also dependent on day of the year as well as time of day. It may be that we eventually include actual data on incident light levels (which include effects such as cloud cover). This might be important if we want to reproduce physical conditions for a particular year.

Individuals in Simulation 2 did not differ as significantly between the null model and the alternative model, as they did in Simulation 1, between a model with no spatial variability and one including spatial variability. There could be several reasons for this discrepancy. First, there were some differences in the way temperature was calculated in the versions of the SPEM model used for Simulation 1 versus Simulation 2, so the model-derived temperature fields were not exactly the same for both. Temperature varied more in Simulation 1, both horizontally and vertically. Second, because Lagrangian float tracking over irregular bathymetry frequently involves large depth changes for each float, individuals experienced more variability in depth, and therefore more variance in temperature, in Simulation 1 (in Simulation 2, the complex depth algorithm kept individuals within a more limited depth range). The larger spatial variation in temperature in Simulation 1 resulted in even greater differences in growth than were seen in Simulation 2. These differences underscore the importance of an accurate depth program for individual fish in the model.

There are several other factors which will affect spatial variability in growth and other life history attributes that are not yet included in this preliminary version of the IBM. First, there is no spatial variability in food or predators in this model. Spatial variation in food will undoubtedly cause spatial variation in growth. Spatial variation in mortality, either due to starvation or predation (both of which will be included in later versions of the model) will also result in more variability, especially if predation is size-based. Note that there is no mortality in Simulation 2, whereas there is a constant mortality within each life stage in Simulation 1. In Simulation 1, individuals seeded in areas with colder water experienced extended stage durations, therefore higher cumulative mortalities, and this affected the size distributions by selectively eliminating a group of individuals with a particular temperature history.

Our coupled biophysical model is now producing spatial distributions of the first 3 life stages of walleye pollock and reproducing growth and other biological characteristics in a reasonable manner. As shown by Simulation 3, the model also qualitatively reproduces downstream movement of these early life stages from the spawning area in Shelikof Strait to the juvenile nursery area near the Shumagin Islands. The predicted patterns closely resemble observed patterns, and show a degree of horizontal complexity in the distributions of pollock life stages that is comparable to that seen in the field. More comparisons of model output with data for other years are presented in Hermann et al. (1996). Further development of the biological model is in progress, so that we may examine the specific interactions of biotic and abiotic processes thought to affect recruitment.

The coupled biophysical model presented here consists of a detailed 3-dimensional hydrodynamic model and an i-state configuration IBM containing significant biological detail. Very few i-state configuration IBMs have included detailed dynamic spatial information along with the biological detail (Tyler \& Rose 1994). Many of the early IBMs were developed within the CompMech (Compensatory Mechanisms in Fish Populations) program funded by the Electric Power Research Institute, however most of these models characterize the habitat as a homogenous unit (Tyler \& Rose 1994), where abiotic factors may either be constant or time-varying. An early biophysical model of walleye pollock larvae (which included a biological IBM), was developed by Walsh et al. (1981), however, both the physics and the biology were very simple. Bartsch et al. (1989) developed a model to describe the movement through the North Sea of herring larvae, which combined a 3-dimensional circulation model with an extremely simple biological IBM. Larvae were represented as 'tracer particles' which were moved by advective forces. The biology was limited to a simplified vertical movement using mean daytime and nighttime depths from observations, and spawning areas and times. Walters et al. (1992) describe a biophysical model similar to Bartsch's for English sole larvae in British Columbia, Canada. Werner et al. (1993) developed a biophysical model of advection and behavior of cod and haddock early life stages on Georges Bank. This model consisted of a finite element circulation model which produced a steady state circulation field. The biology consisted of simple vertical distributions by life stage, some horizontal movement of later stage larvae, and spawning distributions. This model was 
further developed (under the auspices of the U.S. Global Ocean Ecosystem Dynamic (GLOBEC) program; Werner et al. 1995) and now includes more biological detail in the IBM, such as feeding, growth and starvation mortality. Development of biophysical modeling techniques which combine both detailed circulation models with biological IBMs will most likely occur rapidly in the near future. Several other large-scale fisheries recruitment programs such as NOAA's Coastal Ocean Program and the Canadian Ocean Production Enhancement Network (OPEN) program have biophysical modeling efforts of this sort underway at this time. This approach shows promise in clarifying mechanisms affecting recruitment processes and year-to-year variations in year-class strength of marine fish.

Acknowledgements. This research was conducted as part of the Fisheries Oceanography Coordinated Investigations (FOCI) Program (NOAA, Seattle): FOCl contribution no. 0224. We thank $\mathrm{K}$. Rose for inspiration and guidance in the modeling, and R. Francis and K. Rose for reviewing this manuscript. The Electric Power Research Institute Fellowship Program provided partial support for S.H. to conduct this research. Many people in the FOCI program very generously provided data and parameters for this model and were helpful in discussions of this work.

\section{LITERATURE CITED}

Appenzeller AR, Leggett WC (1995) An evaluation of lightmediated vertical migration of fish based on hydroacoustic analysis of the diel vertical movements of rainbow smelt (Osmerus mordax). Can J Fish Aquat Sci 52:504-511

Bailey KM, Spring SM (1992) Comparison of larval, age-0 juvenile and age- 2 recruit abundance indices of walleye pollock, Theragra chalcogramma, in the western Gulf of Alaska. ICES J Mar Sci 49:297-304

Bailey KM. Stehr CL (1986) Laboratory studies on the early life history of the walleye pollock, Theragra chalcogramma (Pallas). J Exp Mar Biol Ecol 99:233-246

Bartsch J, Brander $K$, Heath M, Munk P, Richardson K, Svendsen E (1989) Modelling the advection of herring larvae in the North Sea. Nature 340:632-636

Blood DM, Matarese AC, Yoklavich MM (1994) Embryonic development of walleye pollock Theragra chalcogramma, from Shelikof Strait, Gulf of Alaska. Fish Bull US 92: $207-222$

Bograd SJ, Stabeno PJ, Schumacher JD (1994) A census of mesoscale eddies in Shelikof Strait, Alaska, during 1989 J Geophys Res 99:18243-18254

Brett JR, Groves TDD (1979) Physiological energetics. In Hoar WS, Randall DJ, Brett JR (eds) Fish physiology, Vol 8 Academic Press, New York, p 279-352

Caswell H, John AM (1992) From the individual to the population in demographic models. In: DeAngelis DL, Gross LJ (eds) Individual-based models and approaches in ecology. populations, communities, and ecosystems. Routledge, Chapman and Hall, Inc, New York, p 36-61

Chambers RC (1993) Phenotypic variability in fish populations and its representation in individual-based models Trans Am Fish Soc 122:404-41.4
Checkley DM Jr (1984) Relation of growth to ingestion for larvae of Atlantic herring Clupea harengus and other fish Mar Ecol Prog Ser 18:215-224

DeAngelis DL, Godbout L, Shuter BJ (1991) An individualbased approach to predicting density-dependent dynamics in smallmouth bass populations. Ecol Model 57: 91-115

DeAngelıs DL، Gross LJ (1992) Individual-based models and approaches in ecology: populations, communities, and ecosystems. Routledge, Chapman and Hall, Inc, New York

DeAngelis DL, Rose KA (1992) Which individual-based approach is most appropriate for a given problem? In: DeAngelis DL, Gross LJ (eds) Individual-based models and approaches in ecology: populations, communities, and ecosystems. Routledge, Chapman and Hall, Inc, New York, p $67-87$

DeBlois EM, Leggett WC (1993) Match/mismatch between the abundance of marine fish eggs and invertebrate predators: an analysis of Calliopius laeviusculus (Amphipoda: Gammaridae) population growth relative to the seasonal spawning cycle of capelin (Mallotus villosus). Can J Fish Aquat Sci 50:2581-2590

Frank KT, Leggett WC (1982) Coastal water mass replacement: its effect on zooplankton dynamics and the predator-prey complex associated with larval capelin (Mallotus villosus).Can J Fish Aquat Sc1 39:991-1003

Haidvogel DB, Wilkin JL, Young R (1991) A semi-spectral primitive equation ocean circulation model using vertical sigma and orthogonal curvilinear horizontal coordinates. J Comput Physics 94:151-185

Haynes EG, Ignell SE (1983) Effect of temperature on the rate of embryonic development of walleye pollock. Theragra chalcogramma. Fish Bull US 81:890-894

Hedstrom KS (1994) User's manual for a semi-spectral primitive equation model, version 3.9. Institute of Marine and Coastal Sciences, Rutgers, The State University of New Jersey, New Brunswick

Hermann AJ, Hinckley S, Megrey BA, Stabeno PJ (1996) Interannual variability of the early life history of walleye pollock near Shelikof Strait as inferred from a spatially explicit, individual-based model. Fish Oceanogr 5(Suppl 1) $39-57$

Hermann AJ, Stabeno PJ (1996) An eddy resolving model of circulation on the western Gulf of Alaska shelf. I. Model development and sensitivity analyses. J Geophys Res 101. $1129-1149$

Hinckley S (1990) Variation of egg size of walleye pollock (Theragra chalcogramma) with a preliminary examination of the effect of egg size on larval size. Fish Bull US 88: $471-483$

Hjort J (1914) Fluctuations in the great fisheries of northern Europe. Rapp PV Reun Cons Int Explor Mer 20:1-20

Hjort J (1926) Fluctuations in the year classes of important food fishes. J Cons int Explor Mer 1:5-38

Houde ED (1989) Comparative growth, mortality, and energetics of marine fish larvae: temperature and umplied latitudinal effects. Fish Bull US 87:471-495

Houde ED, Shekter RC (1981) Growth rates, rations and cohort consumption of marine fish larvae in relation to prey concentration. Rapp PV Réun Cons Int Explor Mer 178:441-453

Huston MA, DeAngelis DL, Post WM (1988) New computer models unify ecological theory. BioScience 38:682-691

Incze LS. Kendall AW, Schumacher JD, Reed RK (1989) Interactions of a mesoscale patch of larval fish (Theragra chalcogramma) with the Alaska Coastal Current. Cont Shelf Res 9:269-284 
Judson OP (1994) The rise of the individual-based model in ecology. Trends Ecol Evol 9:9-14

Kändler R, Tan EO (1965) Investigations on the osmoregulation in pelagic eggs of gadoid and flatfishes in the Baltic. Part 1 . Changes in volume and specific gravity at different salinities. ICES Baltic-Belt Council Meeting 43

Kendall AW, Clarke ME, Yoklavich MM, Boehlert GW (1987) Distribution, feeding, and growth of larval walleye pollock, Theragra chalcogramma, from Shelikof Strait, Gulf of Alaska. Fish Bull US 85:499-521

Kendall AW, Incze LS, Ortner PB, Cummings SR, Brown PK (1994) The vertical distribution of eggs and larvae of walleye pollock (Theragra chalcogramma) in Shelikof Strait, Gulf of Alaska. Fish Bull US 92:540-554

Kendall AW, Kim S (1989) Buoyancy of walleye pollock (Theragra chalcogramma) eggs in relation to water properties and movement in Shelikof Strait, Gulf of Alaska. In: Beamısh RJ, McFarlane GA (eds) Effects of ocean variabılity on recruitment and an evaluation of parameters used in stock assessment models. Can Spec Publ Fish Aquat Sci 108:169-180

Kendall AW, Nakatani T (1992) Comparısons of early life-history characteristics of walleye pollock Theragra chalcogramma in Shelikof Strait, Gulf of Alaska, and Funka Bay, Hokkaido, Japan. Fish Bull US 90:129-138

Kiorboe T, Munk P, Richardson K (1987) Respiration and growth in larval herring Clupea harengus: relation between specific dynamic action and growth efficiency. Mar Ecol Prog Ser 40:1-10

Komnicki A (1992) Population ecology from the individual perspective. In: DeAngelis DL, Gross LJ (eds) Individualbased models and approaches in ecology: populations, communities, and ecosystems. Routledge, Chapman and Hall, Inc, New York, p 3-17

Lasker R (1978) The relation between oceanographic conditions and larval anchovy food in the California Current: identification of factors contributing to recruitment failure. Rapp PV Réun Cons lnt Explor Mer 173:212-230

Leggett WC. Frank KT, Carscadden JE (1984) Meteorological and hydrographic regulation of year-class strength in capelin (Mallotus villosus). Can J Fish Aquat Sci 41. $1193-1201$

MacKenzie BR, Leggett WC, Peters RH (1990) Estumating larval fish ingestion rates: can laboratory derived values be reliably extrapolated to the wild? Mar Ecol Prog Ser 67 $209-225$

MacKenzie BR, Miller TJ, Cyr S, Leggett WC (1994) Evidence for a dome-shaped relationship between turbulence and larval fish ingestion rate. Limnol Oceanogr 39:1790-1799

Metz JA, Diekmann O (1986) The dynamics of physiologically structured populations. Lecture notes in biomathematics. Vol 68. Springer-Verlag, Berlin

Neill WH (1979) Mechanisms of fish distribution in heterothermal environments. Am Zool 19:305-317

Neilson JD, Perry RI (1990) Diel vertical migrations of marine fishes: an obligate or facultative process? Adv Mar Biol 26: $115-168$

Nisbet RM, Gurney SC (1982) Modelling fluctuating populations. John Wiley \& Sons, New York

Olla BL, Davis MW (1990) Effects of physical factors on the vertical distribution of larval walleye pollock Theragra chalcogramma under controlled laboratory conditions. Mar Ecol Prog Ser 63:105-112

Page FH, Frank KT, Thompson K (1989) Stage dependent vertical distribution of haddock (Melanogrammus aeglefinus) eggs in a stratified water column: observations and model. Can J Fish Aquat Sci 46(Suppl 1):55-67
Pepin P, Miller TJ (1993) Potential use and abuse of general empirical models of early life history processes in fish. Can J Fish Aquat Sci 50:1343-1345

Pritchett M. Haldorson L (1989) Depth distribution and vertical migration of larval walleye pollock (Theragra chalcogramma). In: Proceedings of the international symposium on the biology and management of walleye pollock; 14-16 November 1988, Anchorage. Alaska Sea Grant Rep 89-1, Unıversity of Alaska, Fairbanks, Alaska, p 173-183

Rice JA, Miller TJ, Rose KA, Crowder LB, Marschall EA, Trebitz AS, DeAngelis DL (1993) Growth rate variation and larval survival: inference from an individual-based size-dependent predation model. Can J Fish Aquat Sci 50: $133-142$

Rose KA, Cowan JH Jr (1993) Individual-based model of young-of-the-year striped bass population dynamics. I. Model description and baseline simulations. Trans Am Fish Soc 122:415-430

Rothschild BJ, Osborn TR (1988) Small-scale turbulence and plankton contact rates. J Plankton Res 10:465-474

Savage D (1990) Fisheries Oceanography Coordinated Investigations Field Operations 1989. NOAA Data Rep ERL PMEL-26

Schumacher JD, Stabeno PJ, Bograd SJ (1993) Characteristics of an eddy over a continental shelf: Shelikof Strait, Alaska. J Geophys Res 98:8395-8404

Sclafani M. Taggart CT, Thompson KR (1993) Condition, buoyancy and the distribution of larval fish: implications for vertical migration and retention. J Plankton Res 15: $413-435$

Smith M (1974) Models in ecology. Cambridge University Press, Cambridge

Solemdal P (1967) The effect of salinity on buoyancy, size and development of flounder eggs. Sarsia 29:431-442

Solemdal P (1973) Transfer of Baltic flatfish to a marine environment and the long-term effects on reproduction. Oikos Suppl 15:268-276

Stabeno PJ, Hermann Aj (1996) An eddy resolving model of circulation on the western Gulf of Alaska shelf II. Comparison of results to oceanographic observations. J Geophys Res 101:1151-1161

Stabeno PJ, Hermann AJ, Bond NA, Bograd SJ (1995) Modelling the possible impact of climate change on the survival of larval walleye pollock (Theragra chalcogramma) in the Gulf of Alaska. In: Beamish RJ (ed) Climate change and northern fish populations. Can Spec Pub Fish Aquat Sci 121:719-727

Stabeno PJ, Schumacher JD, Bailey KM, Brodeur RD, Cokelet ED (1996) Observed patches of walleye pollock eggs and larvae in Shelikof Strant, Alaska: their characteristics, formation and persistance. Fish Oceanogr 5(Suppl 1):81-91

Sundby S (1983) A one-dimensional model for the vertical distribution of pelaglc fish eggs in the mixed layer. Deep Sea Res 30:645-661

Theilacker GH, Kimball AS (1984) Comparative quality of rotifers and copepods as foods for larval fishes. Calif Coop Ocean Fish Invest Rep 15:80-86

Tyler JA, Rose KA (1994) Individual variability and spatial heterogeneity in fish population models. Rev Fish Biol Fish 4.91-123

Van Winkle W, Rose KA, Chambers RC (1993) Individualbased approach to fish population dynamics: an overview. Trans Am Fish Soc 122:397-403

WaIsh JJ, Wirick CD, Dieterle DA, Tingle AG (1981) Environmental constraints on larval fish survival in the Bering Sea. Rapp PV Réun Cons Int Explor Mer 178:24-27 
Walters CJ, Hannah CG, Thompson K (1992) A microcomputer program for simulating effects of the physical transport process on fish larvae. Fish Oceanogr 1: $11-19$

Webb PW (1978) Partitioning of energy into metabolism and growth. In: Gerking SD (ed) Ecology of freshwater fish production. Wiley, New York, p 184-214

Werner FE, Page FH, Lynch DR, Loder JW, Lough RG. Perry RI, Greenberg DA, Sinclair MM (1993) Influences of mean advection and simple behavior on the distribution of cod

This article was submitted to the editor and haddock early life stages on Georges Bank. Fish Oceanogr 2:43-64

Werner FE, Perry RI, Lough RG, Naimie CE (1995) Trophodynamic and advective influences on Georges Bank larval cod and haddock. Deep Sea Res II, Topical Studies in Oceanography, Georges Bank Research Volume (in press)

Yamashita Y, Bailey KM (1989) A laboratory study of the bioenergetics of larval walleye pollock, Theragra chalcogramma. Fish Bull US 87:525-536

Manuscript first received: January 20,1995

Revised version accepted: March 8, 1996 